\title{
MODELING GROSS PRIMARY PRODUCTION OF AN EVERGREEN NEEDLELEAF FOREST USING MODIS AND CLIMATE DATA
}

\author{
Xiangming Xiao, ${ }^{1,3}$ Qingyuan Zhang, ${ }^{1}$ David Hollinger, ${ }^{2}$ John Aber, ${ }^{1}$ And Berrien Moore III ${ }^{1}$
}

${ }^{1}$ Institute for the Study of Earth, Oceans and Space, University of New Hampshire, Durham, New Hampshire 03824 USA

${ }^{2}$ USDA Forest Service, Northeastern Research Station, 271 Mast Road, Durham, New Hampshire 03824 USA

Abstract. Forest canopies are composed of photosynthetically active vegetation (PAV, chloroplasts) and nonphotosynthetic vegetation (NPV, e.g., cell wall, vein, branch). The fraction of photosynthetically active radiation (PAR) absorbed by the canopy (FAPAR) should be partitioned into FAPAR $\mathrm{PAV}$ and FAPAR $_{\mathrm{NPV}}$. Gross primary production (GPP) of forests is affected by FAPAR $\mathrm{PAV}_{\mathrm{PA}}$. In this study we developed and validated a satellite-based vegetation photosynthesis model (VPM; GPP $\left.=\varepsilon_{\mathrm{g}} \times \mathrm{FAPAP}_{\mathrm{PAV}} \times \mathrm{PAR}\right)$ that incorporates improved vegetation indices derived from the moderate resolution imaging spectroradimeter (MODIS) sensor. Site-specific data from the $\mathrm{CO}_{2}$ flux tower site (evergreen needleleaf forest) at Howland, Maine, USA, were used. The enhanced vegetation index (EVI) better correlated with the seasonal dynamics of GPP than did the normalized difference vegetation index (NDVI). Simulations of the VPM model were conducted, using both daily and eight-day composites of MODIS images (500-m spatial resolution) and climate data (air temperature and PAR), respectively. Predicted GPP values in 2001 agree reasonably well with estimated GPP from the $\mathrm{CO}_{2}$ flux tower site. There were no significant differences in VPM-predicted GPP (from eight-day MODIS composites) among one pixel ( $\sim 500$-m resolution), $3 \times 3$ pixel block $(\sim 1.5-\mathrm{km}$ resolution), and $5 \times 5$ pixel block $(\sim 2.5-\mathrm{km}$ resolution). The differences between VPM-predicted and observed GPP were smaller for simulations using eight-day MODIS composites than for simulations using daily MODIS images. The results of this study have shown the potential of MODIS data (both daily and eight-day composites) and the VPM model for quantifying seasonal and interannual variations of GPP of evergreen needleleaf forests.

Key words: $\quad \mathrm{CO}_{2}$ flux; Howland Forest (Maine, USA); vegetation photosynthesis model.

\section{INTRODUCTION}

Leaf and canopy photosynthesis is one of the key processes of the carbon cycle in the terrestrial ecosystems and requires photosynthetically active radiation (PAR), $\mathrm{CO}_{2}$, water, and nutrients. Vegetation canopies intercept various amounts of PAR over the plant-growing season because of differences in leaf types and seasonal dynamics of leaf phenology (leaf flush, leaf expansion, senescence, leaf fall). For decades, numerous studies have focused on estimating the fraction of PAR (FAPAR) absorbed by vegetation canopies. In the process-based modeling approach, leaf area index (LAI) and light extinct coefficients are used to estimate canopy FAPAR. A number of process-based global biogeochemical models do not explicitly calculate FAPAR, but compute a leaf area index (Ruimy et al. 1999). For those global models, FAPAR can be estimated as a function of LAI and light extinction coefficient $(k)$ (Ruimy et al. 1999):

$$
\mathrm{FAPAR}=0.95\left(1-e^{-k \times \mathrm{LAI}}\right) .
$$

Manuscript received 10 March 2004; revised 11 June 2004; accepted 22 October 2004. Corresponding Editor: I. C. Burke.

${ }^{3}$ E-mail: xiangming.xiao@unh.edu
Numerous remote-sensing studies have also found that leaf area index is closely correlated with satellitederived vegetation indices, for example, the normalized difference vegetation index (NDVI), which is calculated as the normalized difference between reflectance values of near infrared $\left(\rho_{\text {nir }}\right)$ and red $\left(\rho_{\text {red }}\right)$ bands (Tucker 1979):

$$
\text { NDVI }=\frac{\rho_{\text {nir }}-\rho_{\text {red }}}{\rho_{\text {nir }}+\rho_{\text {red }}} .
$$

FAPAR is assumed to be a linear or a nonlinear function of NDVI (Potter et al. 1993, Myneni and Williams 1994, Ruimy et al. 1994, Prince and Goward 1995, Justice et al. 1998). The LAI-NDVI relationship and NDVI-FAPAR relationship (Knyazikhin et al. 1998, Myneni et al. 2002) were developed largely from analysis of images from the advanced very high resolution radiometer (AVHRR) sensor onboard National Oceanic and Atmospheric Administration (NOAA) meteorological satellites, and are also used in the standard LAI/ FAPAR product (MOD15A2; Myneni et al. 2002) from the moderate resolution imaging spectroradiometer (MODIS) onboard the Terra satellite, one of the key optical sensors in the National Aeronautics and Space Administration (NASA) earth observing system. The empirical relationships among LAI, NDVI, and FAPAR 
are the dominant paradigm and the foundation for a number of satellite-based production efficiency model (PEM) that estimate gross primary production (GPP) or net primary production (NPP) of terrestrial ecosystems at the global scale (Potter et al. 1993, Ruimy et al. 1994, Prince and Goward 1995, Justice et al. 1998):

$$
\begin{aligned}
& \mathrm{GPP}=\varepsilon_{\mathrm{g}} \times \text { FAPAR } \times \mathrm{PAR} \\
& \mathrm{NPP}=\varepsilon_{\mathrm{n}} \times \text { FAPAR } \times \mathrm{PAR}
\end{aligned}
$$

where $\varepsilon_{\mathrm{g}}$ and $\varepsilon_{\mathrm{n}}$ are light-use efficiencies (g C/MJ PAR) for calculation of GPP and NPP, respectively.

In comparison to the AVHRR sensor, a new generation of advanced optical sensors (e.g., the VEGETATION (VGT) sensor onboard the SPOT-4 satellite, and the MODIS sensor onboard the Terra and Aqua satellites) has additional spectral bands for the studies of vegetation. For example, among the 36 spectral bands in the MODIS sensor, seven spectral bands are primarily designed for study of vegetation and land surface: blue (459-479 nm), green (545-565 nm), red $(620-670 \mathrm{~nm})$, near infrared $(841-875 \mathrm{~nm}, 1230-1250$ $\mathrm{nm})$, shortwave infrared (1628-1652 nm, 2105-2155 $\mathrm{nm})$. The red and near infrared bands provides daily images of the globe at spatial resolution of $250 \mathrm{~m}$, while the other five bands provide daily images of the globe at spatial resolution of $500 \mathrm{~m}$. Availability of more spectral bands in this new generation of advanced optical sensors offers new opportunity for developing and generating improved vegetation indices for the studies of vegetation.

A few remote sensing studies have explored the combination of blue, red, and near infrared (NIR) bands for development of improved vegetation indices that are related to vegetation greenness (Huete et al. 1997, Govaerts et al. 1999, Gobron et al. 2000). For example, the enhanced vegetation index (EVI) was developed using reflectance values of blue, red, and near infrared bands (Huete et al. 1997). EVI directly adjusts the reflectance in the red band as a function of the reflectance in the blue band $\left(\rho_{\text {blue }}\right)$, accounting for residual atmospheric contamination (e.g., aerosols) and variable soil and canopy background reflectance (Huete et al. 1997):

$$
\mathrm{EVI}=2.5 \times \frac{\rho_{\text {nir }}-\rho_{\text {red }}}{\rho_{\text {nir }}+6 \times \rho_{\text {red }}-7.5 \times \rho_{\text {blue }}+1} .
$$

In addition, some of the spectral bands (e.g., 1230$1250 \mathrm{~nm}, 1628-1652 \mathrm{~nm}$ ) in the MODIS sensor are sensitive to leaf and canopy water content as well as soil moisture. Using image data from various sensors (e.g., Landsat, AVIRIS, Hyperion, VEGETATION, MODIS), a few remote sensing studies have explored the potential of spectral bands that are sensitive to water (Hunt et al. 1987, Hunt and Rock 1989, Gao 1996, Serrano et al. 2000, Ceccato et al. 2001, 2002a, b, Xiao et al. 2002a, $b$, Roberts et al. 2003). A few water-oriented vegetation indices were developed for characterization of leaf and canopy water content, e.g., moisture stress index (MSI; Hunt and Rock 1989), normalized difference water index (NDWI, Gao 1996), and land surface water index (LSWI; Xiao et al. 2002a, $b$ ):

$$
\begin{aligned}
\text { MSI } & =\frac{\rho_{\text {swir }}}{\rho_{\text {nir }}} \\
\text { LSWI } & =\frac{\rho_{\text {nir }}-\rho_{\text {swir }}}{\rho_{\text {nir }}+\rho_{\text {swir }}} \\
\text { NDWI } & =\frac{\rho_{0.86}-\rho_{1.24}}{\rho_{0.86} \pm \rho_{1.24}} .
\end{aligned}
$$

The routine operation of the advanced optical sensors (e.g., MODIS and VGT) provides abundant image data that can be used to generate improved vegetation indices (e.g., EVI, LSWI, and NDWI). In this study, our objective was to develop and validate a new satellitebased vegetation photosynthesis model (VPM) that incorporates improved vegetation indices from the advanced optical sensors (e.g., MODIS). We ran the VPM model using both daily and eight-day composites of MODIS images. For evaluation of the VPM model, we used field data collected at an eddy flux tower site $\left(45.20407^{\circ} \mathrm{N}, 68.7402^{\circ} \mathrm{W}\right)$ in Howland Forest, Maine, USA, where evergreen coniferous trees dominate (Hollinger et al. 1999). The vegetation of this 90 -year-old evergreen needleleaf forest is about $41 \%$ red spruce (Pinus rubens Sarg), 25\% eastern hemlock (Tsuga canadensis (L.) Carr.), 23\% other conifers, and 11\% hardwoods (Hollinger et al. 1999). The leaf area index (LAI) of the forest stand is $\sim 5.3 \mathrm{~m}^{2} / \mathrm{m}^{2}$. Plant-growing season usually starts around mid-April ( $\sim$ day of year $100)$ and lasts about 180 days. Eddy flux measurements of $\mathrm{CO}_{2}, \mathrm{H}_{2} \mathrm{O}$, and energy at the site have being conducted since 1996 (Hollinger et al. 1999, 2004) and are part of the AmeriFlux network data (available online). ${ }^{4}$ Forest flux towers provide integrated measurements of net ecosystem exchange (NEE) of $\mathrm{CO}_{2}$ between forests and the atmosphere at relatively large footprint (e.g., hundreds of meters to $1 \mathrm{~km}$ in radius, largely dependent upon height of the tower and winds) that are comparable with the spatial resolution of medium-resolution sensors (e.g., MODIS, VGT). At the ecosystem scale, gross primary production (GPP) and ecosystem respiration (sum of autotrophic respiration and heterotrophic respiration) vary over seasons and determine NEE between the atmosphere and terrestrial ecosystems. $\mathrm{CO}_{2}$ flux data from the tower sites provide valuable information on seasonal dynamics and interannual variation of GPP of forests (Wofsy et al. 1993, Goulden et al. 1997, Hollinger et al. 1999, 2004, Barford et al. 2001). Accurately estimating the spatial patterns and temporal dynamics of GPP or net primary production (NPP) of terrestrial ecosystems at the global scale is of great interest to human society and is necessary for understanding the carbon cycle of the terrestrial bio-

\footnotetext{
${ }^{4}\langle$ http://public.ornl.gov/ameriflux/Data/index.cfm $\rangle$
} 


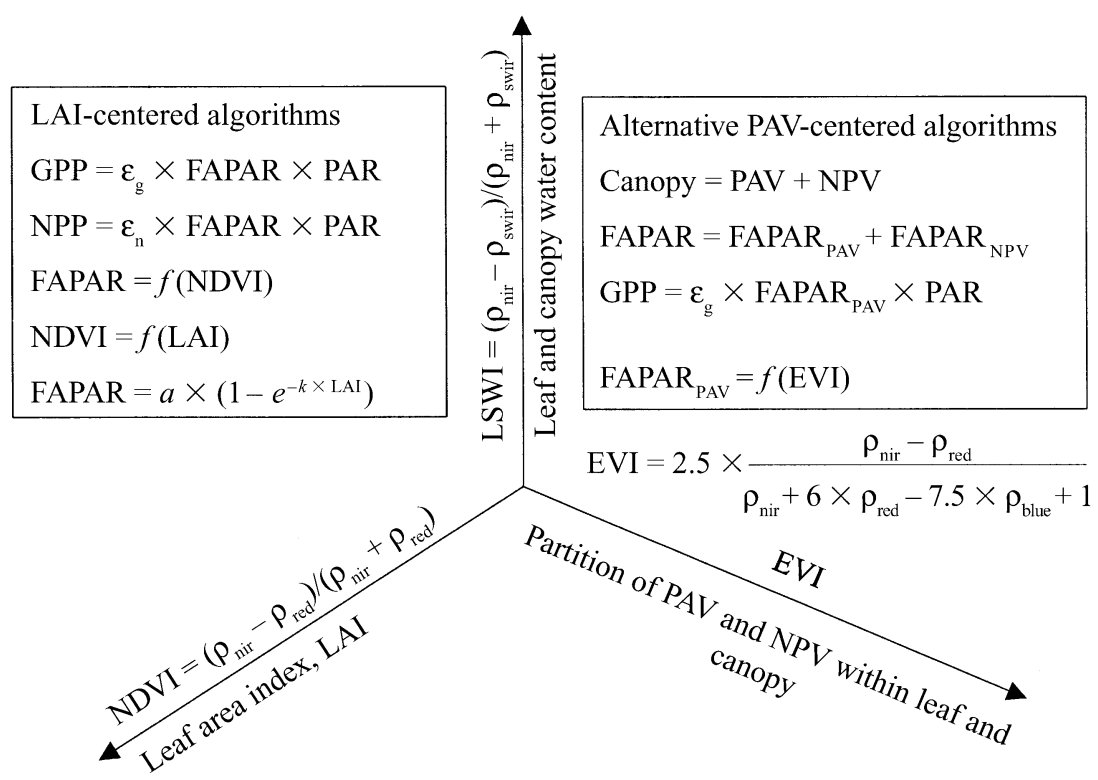

FIG. 1. A summary of the satellite-based approaches for estimating gross primary production (GPP) of terrestrial ecosystems. Abbreviations are: FAPAR, fraction of absorbed PAR (photosynthetically active radiation); NDVI, normalized difference vegetation index; LAI, leaf area index; EVI, enhanced vegetation index; PAV, photosynthetically active vegetation (e.g., green leaves); NPV, nonphotosynthetic vegetation (mostly senescent foliage, stems, and branches). For subscripts of $\rho$ : nir, near infrared; swir, shortwave infrared.

sphere. Our long-term objective is to develop an improved MODIS-based VPM model for quantifying the spatial patterns and temporal changes in GPP of terrestrial ecosystems at the large spatial scales.

\section{Description of Satellite-Based Vegetation Photosynthesis Model (VPM)}

\section{Model structure}

Leaf and forest canopies are composed of photosynthetically active vegetation (PAV, chloroplasts) and nonphotosynthetic vegetation (NPV, mostly senescent foliage, branches, and stems). In some earlier works, forest canopy was partitioned into green leaves and NPV (branches and stems) components (Asner et al. 1998). The presence of NPV has a significant effect on FAPAR at the canopy level. For example, in forests with a leaf area index (LAI) of $<3.0$, NPV (stems) increased canopy FAPAR by $10-40 \%$ (Asner et al. 1998). Within a green leaf, there is some proportion of nonphotosynthetic components (e.g., primary, secondary, and tertiary veins, cell walls), dependent upon leaf type and leaf age. Light absorption of nonphotosynthetic components within a leaf can vary in magnitude (e.g., 20-50\%), dependent upon species, leaf morphology, leaf age, and growth history (Hanan et al. 1998, 2002, Lambers et al. 1998). Therefore, forest canopy FAPAR should be partitioned into two components:

$$
\mathrm{FAPAR}=\mathrm{FAPAR}_{\mathrm{PAV}}+\mathrm{FAPAR}_{\mathrm{NPV}} .
$$

Note that only the photosynthetically active radiation (PAR) absorbed by PAV (FAPAR PAV ) is used for pho- tosynthesis. Partitioning of FAPAR into FAPAR PAV $_{\text {and }}$ and FAPAR $_{\mathrm{NPV}}$ is a critical issue, but it has not been discussed extensively in the remote sensing community. Any model that accounts for FAPAR PAV $_{\text {is likely to }}$ substantially improve estimation of GPP or NPP of forests, given a known value of light-use efficiency $\left(\mu \mathrm{mol} \mathrm{CO}_{2} / \mu \mathrm{mol}\right.$ PAR or $\mathrm{g} \mathrm{C} / \mathrm{MJ}$ PAR) of forests.

Based on the conceptual partition of NPV and PAV within leaf and canopy, we proposed a new satellitebased vegetation photosynthesis model (Xiao et al. $2004 a, b)$ for estimation of GPP over the photosynthetically active period of vegetation (Fig. 1):

$$
\mathrm{GPP}=\varepsilon_{\mathrm{g}} \times \mathrm{FAPAR}_{\mathrm{PAV}} \times \mathrm{PAR}
$$

where PAR is the photosynthetically active radiation, here expressed as a flux density ( $\mu$ mol photosynthetic photon flux $\left.\cdot \mathrm{m}^{-2} \cdot \mathrm{s}^{-1}\right)$, and $\varepsilon_{\mathrm{g}}$ is the light use efficiency ( $\mu \mathrm{mol} \mathrm{CO}_{2} / \mu \mathrm{mol}$ PAR).

Photosynthetic activity of vegetation canopy is in part determined by the amount of PAR absorbed by PAV for photosynthesis. To accurately estimate FA$\mathrm{PAR}_{\mathrm{PAV}}$ in forests is a challenge to both radiative transfer modeling and field measurements. In this version

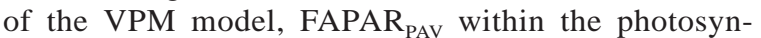
thetically active period of vegetation is estimated as a linear function of EVI, and the coefficient $a$ is set to be 1.0 (Xiao et al. 2004a, $b$ ):

$$
\mathrm{FAPAR}_{\mathrm{PAV}}=a \times \mathrm{EVI} .
$$

Light use efficiency $\left(\varepsilon_{g}\right)$ is affected by temperature, water, and leaf phenology:

$$
\varepsilon_{\mathrm{g}}=\varepsilon_{0} \times T_{\text {scalar }} \times W_{\text {scalar }} \times P_{\text {scalar }}
$$


where $\varepsilon_{0}$ is the apparent quantum yield or maximum light use efficiency ( $\mu \mathrm{mol} \mathrm{CO} / \mu \mathrm{mol} \mathrm{PAR})$, and $T_{\text {scalar }}$, $W_{\text {scalar }}$, and $P_{\text {scalar }}$ are the downward-regulation scalars for the effects of temperature, water and leaf phenology (age) on light use efficiency of forests, respectively.

$T_{\text {scalar }}$ is estimated at each time step, using the equation developed for the terrestrial ecosystem model (Raich et al. 1991):

$$
T_{\text {scalar }}=\frac{\left(T-T_{\min }\right)\left(T-T_{\max }\right)}{\left[\left(T-T_{\min }\right)\left(T-T_{\max }\right)\right]-\left(T-T_{\mathrm{opt}}\right)^{2}}
$$

where $T_{\min }, T_{\max }$, and $T_{\mathrm{opt}}$ are minimum, maximum, and optimal temperature for photosynthetic activities, respectively. If air temperature falls below $T_{\min }, T_{\text {scalar }}$ is set to be zero.

$W_{\text {scalar }}$, the effect of water on plant photosynthesis, has been estimated as a function of soil moisture and/ or water vapor pressure deficit (VPD) in a number of PEM models (Field et al. 1995, Prince and Goward 1995, Running et al. 2000). For instance, in the CASA (Carnegie, Stanford, Ames Approach) model, soil moisture was estimated using a one-layer bucket model (Malmstrom et al. 1997). Soil moisture represents water supply to the leaves and canopy, and water vapor pressure deficit represents evaporative demand in the atmosphere. Leaf and canopy water content is largely determined by dynamic changes of both soil moisture and water vapor pressure deficit. The availability of time-series data of SWIR and NIR bands from the new generation of advanced optical sensors (e.g., VGT, MODIS) offers opportunities for quantifying canopy water content at large spatial scales through both the vegetation indices approach (Ceccato et al. 2002b) and the radiative transfer modeling approach (Zarco-Tejada et al. 2003). Vegetation indices that are based on NIR and SWIR bands are sensitive to change in equivalent water thickness $\left(\mathrm{g} / \mathrm{cm}^{2}\right)$ at leaf and canopy levels (Hunt and Rock 1989, Ceccato et al. 2001, 2002a, b). As the first order of approximation, here we proposed an alternative and simple approach that uses a satellite-derived water index to estimate the seasonal dynamics of $W_{\text {scalar: }}$ :

$$
W_{\text {scalar }}=\frac{1+\text { LSWI }}{1+\text { LSWI }_{\max }}
$$

where $\mathrm{LSWI}_{\max }$ is the maximum LSWI within the plantgrowing season for individual pixels.

$P_{\text {scalar, }}$, the effect of leaf phenology on photosynthesis, is defined by vegetation types (Xiao et al. 2004a, $b$ ). Evergreen needleleaf trees in temperate and boreal zones have a green canopy throughout the year, because foliage is retained for several growing seasons. The canopy of evergreen needleleaf forests is thus composed of green leaves of various ages. To deal with different age classes in evergreen forest canopies, fixed turnover rates of foliage of evergreen needleleaf forests at canopy level have been used in some process-based ecosystem models (Aber and Federer 1992, Law et al. 2000). For evergreen needleleaf forest, we simply assumed $P_{\text {scalar }}=1$ (Xiao et al. 2004a).

\section{Estimation of model parameters}

In order to obtain $\varepsilon_{0}$ value of evergreen needleleaf forests for the VPM model, a literature survey was conducted to gather published information on $\varepsilon_{0}$ for evergreen needleleaf forests, in those publications that $\varepsilon_{0}$ values were estimated using the nonlinear hyperbolic function (Ruimy et al. 1995). The boreal ecosystematmosphere study (BOREAS) conducted $\mathrm{CO}_{2}$ flux measurement at a few evergreen needleleaf forest sites in Canada. During 16 March 1994-31 October 1996, the eddy covariance technique was used to measure net ecosystem exchange of $\mathrm{CO}_{2}$ between the atmosphere and a black spruce (Picea mariana) forest in central Manitoba, Canada (Goulden et al. 1997). The site $\left(55.879^{\circ} \mathrm{N}, 98.484^{\circ} \mathrm{W}\right)$ is dominated by $10 \mathrm{~m}$ tall, 120 year-old black spruce, with a minor layer of shrubs and continuous feather moss. Through examination of the relationship between GPP and incident PAR, it was reported that apparent quantum yield for the tower site is $\varepsilon_{0}=0.040 \mu \mathrm{mol} \mathrm{CO} / \mu \mathrm{mol}$ PAR (Goulden et al. 1997). In this study, we used $\varepsilon_{0}=0.040 \mu \mathrm{mol} \mathrm{CO} \mathrm{CO}_{2} /$ $\mu \mathrm{mol}$ PAR, or $0.48 \mathrm{~g} \mathrm{C} / \mathrm{mol}$ PAR for evergreen needleleaf forest (Goulden et al. 1997). The $\varepsilon_{0}=0.040$ $\mu \mathrm{mol} \mathrm{CO}_{2} / \mu \mathrm{mol}$ PAR value was also used in the threePG model that uses leaf area index to calculate FAPAR of a Pinus ponderosa forest (Law et al. 2000). Table 1 compares $\varepsilon_{0}$ values used in a few PEM models.

In calculation of $T_{\text {scalar }}$ (Eq. 13), $T_{\min }, T_{\text {opt }}$, and $T_{\max }$ values vary among different vegetation types (Raich et al. 1991, Aber and Federer 1992). For evergreen needleleaf forest, we use $0^{\circ} \mathrm{C}, 20^{\circ} \mathrm{C}$ and $40^{\circ} \mathrm{C}$ for $\mathrm{T}_{\min }, \mathrm{T}_{\text {opt }}$ and $\mathrm{T}_{\max }$, respectively (Aber and Federer 1992). In calculation of $W_{\text {scalar }}$ (Eq. 14), a pixel-specific LSWI max $_{\text {max }}$ value is selected from the time series of LSWI values within the plant-growing season.

\section{Satellite Images and Field Data MODIS images}

The MODIS land science team provides a suite of eight-day composite products (available online), ${ }^{5}$ including the eight-day surface reflectance product (MOD09A1) and the eight-day LAI/FAPAR product (MOD15A2). The LAI/FAPAR products were derived from the LAI/FAPAR algorithms described by (Knyazikhin et al. 1998). Both the MODIS surface reflectance and FAPAR datasets have a spatial resolution of $500 \mathrm{~m}$ and are provided to users in a tile fashion where each tile covers an area of $10^{\circ}$ latitude by $10^{\circ}$ longitude. The Howland Forest site is within the tile H13V04. We downloaded the standard eight-day surface reflectance data (MOD09A1) and the eight-day LAI/FAPAR data from January 2001 to December 2002 (collection 3 of

\footnotetext{
${ }^{5}\langle$ http://modis-land.gsfc.nasa.gov/ $\rangle$
} 
TABLE 1. A comparison of the production efficiency models (PEM) for evergreen needleleaf forest.

\begin{tabular}{|c|c|c|c|c|}
\hline Model & FAPAR & $\varepsilon_{\mathrm{g}}$ or $\varepsilon_{\mathrm{n}}$ & $\varepsilon_{0}$ & Reference \\
\hline \multicolumn{5}{|c|}{ Net primary production, NPP } \\
\hline CASA & FAPAR $=f(\mathrm{NDVI})$ & $\varepsilon_{\mathrm{n}}=\varepsilon_{0} \times T \times \mathrm{SM}$ & 0.11 & Potter et al. (1993) \\
\hline \multicolumn{5}{|c|}{ Gross primary production, GPP } \\
\hline TURC & FAPAR $=f(\mathrm{NDVI})$ & $\varepsilon_{\mathrm{g}}=\varepsilon_{0}$ & 0.24 & Ruimy et al. (1996) \\
\hline GLO-PEM & FAPAR $=f($ NDVI $)$ & $\varepsilon_{\mathrm{g}}=\varepsilon_{0} \times T \times \mathrm{SM} \times \mathrm{VPD}$ & 0.14 & Prince and Goward (1995) \\
\hline MODIS-PSN & $\begin{array}{l}\text { FAPAR }=f(\mathrm{LAI}) \\
\text { FAPAR }=f(\mathrm{NDVI})\end{array}$ & $\varepsilon_{\mathrm{g}}=\varepsilon_{0} \times T \times \mathrm{VPD}$ & 0.22 & Running et al. (2000) \\
\hline 3-PG & FAPAR $=f(\mathrm{LAI})$ & $\varepsilon_{\mathrm{g}}=\varepsilon_{0} \times T \times \mathrm{SM} \times \mathrm{VPD}$ & 0.48 & Law et al. (2000) \\
\hline VPM & $\mathrm{FAPAR}_{\mathrm{PAV}}=f(\mathrm{EVI})$ & $\varepsilon_{\mathrm{g}}=\varepsilon_{0} \times T \times W$ & 0.48 & Xiao et al. (this study) \\
\hline
\end{tabular}

Notes: NPP $=\varepsilon_{\mathrm{n}} \times$ FAPAR $\times$ PAR or GPP $=\varepsilon_{\mathrm{g}} \times$ FAPAR $\times$ PAR or GPP $=\varepsilon_{\mathrm{g}} \times$ FAPAR $_{\mathrm{PAV}} \times$ PAR. Downwardregulation scalars for light use efficiency $\left(\varepsilon_{\mathrm{g}}\right.$ or $\varepsilon_{\mathrm{n}}$, depending on the model) include: temperature (T), soil moisture (SM), water vapor pressure deficit (VPD) and canopy water content $(W)$. Here we list $\varepsilon_{0}(\mathrm{~g} C / \mathrm{mol}$ PAR) for evergreen needleleaf forest, used in those PEM models. Note that some PEM models use g C/MJ for $\varepsilon_{0}$ (Potter et al. 1993, Prince and Goward 1995), and an approximate conversion between energy (PAR, MJ) and photosynthetically active photon flux density (PAR, mol) units is $\sim 4.6$ (Aber et al. 1996). Abbreviations are: FAPAR, fraction of absorbed photosynthetically active radiation; NDVI, normalized difference vegetation index; LAI, leaf area index; EVI, enhanced vegetation index; PAV, photosynthetically active vegetation.

MODIS standard product collection). Note that there were no MODIS data acquisitions during 10 June3 July 2001, because of technical failure of MODIS sensor. The eight-day surface reflectance data set (MOD09A1) has seven spectral bands, and was used to calculate vegetation indices (NDVI, EVI, MSI, NDWI, and LSWI). For a time-series data of vegetation index, we used a simple method (Xiao et al. 2003) to fill vegetation index values for those cloudy pixels identified by the quality flag in the MOD09A1 files. We first selected a three-point time-series filter, $X(t-$ $1), X(t)$ and $X(t+1)$ and used values of noncloudy pixels in this window to correct a cloudy pixel. If both $X(t-1)$ and $X(t-1)$ pixels were cloudfree, we calculated the mean of $X(t-1)$ and $X(t+1)$, and used the mean value to replace $X(t)$. If only one pixel (either $X(t-1)$ or $X(t+1))$ was cloudfree, we used that pixel to replace $X(t)$. If the algorithm did not succeed in a three-point time-series filter, we then extended to a fivepoint time-series filter, $X(t-2), X(t-1), X(t), X(t+$ $1), X(t+2)$, using the same procedure as the above three-point time-series filter.

The geo-location accuracy of the MODIS product is within subpixel level, with an operational goal of 50 $\mathrm{m}(1 \sigma)$ at nadir view (Wolfe et al. 2002). Based on the geolocation information (latitude and longitude) of the $\mathrm{CO}_{2}$ flux tower site at Howland, Maine, MODIS data of surface reflectance, vegetation indices, and FAPAR were extracted from one MODIS pixel, a $3 \times 3$ pixel block, and a $5 \times 5$ pixel block, respectively, centered on the flux tower. Mean and standard deviation of vegetation indices were calculated for both the $3 \times$ 3 pixel block and the $5 \times 5$ pixel block, after excluding cloudy pixels. Our analyses of eight-day MODIS data were (1) to evaluate seasonal dynamics of vegetation indices, FAPAR, and $\mathrm{CO}_{2}$ flux data from the flux tower site; and (2) to run the VPM model and compare the VPM-predicted GPP ( $\mathrm{g} \mathrm{C} / \mathrm{m}^{2}$ in eight days) with the observed GPP from the flux tower site. We used site- specific temperature and PAR data from the flux tower site for simulations of the VPM model.

While our focus is the application of the VPM model for eight-day MODIS images, we are also interested in evaluating the model with daily MODIS images. The MODIS land science team provides daily MODIS surface reflectance product (MOD09GHK; see footnote 5). We downloaded the daily MODIS surface reflectance product of 2001 (collection 3 of MODIS standard products collection). The MOD09GHK dataset provides surface reflectance values of seven spectral bands (the same bands as the eight-day composite MOD09A1 product) for all observations in a day. For simplification, we extracted surface reflectance data of the first observation of individual pixels and then calculated vegetation indices (EVI, LSWI). Our analysis of daily MODIS data is primarily to run the VPM model and compare VPM-predicted GPP (g C.m².day) with observed daily GPP from the flux tower site.

\section{$\mathrm{CO}_{2}$ flux and climate data from the eddy flux tower site}

Eddy flux measurements of $\mathrm{CO}_{2}, \mathrm{H}_{2} \mathrm{O}$, and energy at the Howland site have being conducted since 1996 (Hollinger et al. 1999, 2004; and online resources, see footnote 4). Daily flux data of NEE, GPP, and ecosystem respiration $(R)$ at the Howland site during 19962001 were generated from the half-hourly flux data. Half-hourly values were calculated from the covariance of the fluctuations in vertical wind speed and $\mathrm{CO}_{2}$ concentration measured at $5 \mathrm{~Hz}$ (Hollinger et al. 1999). Half-hourly flux values were excluded from further analysis if the wind speed was below $0.5 \mathrm{~m} / \mathrm{s}$, sensor variance was excessive, rain or snow was falling, for incomplete half-hour sample periods, or instrument malfunction. At night, flux values were excluding from further analysis if the friction velocity $\left(u^{*}\right)$ was below a threshold of 0.25 . To obtain annual estimates of $\mathrm{CO}_{2}$ exchange, values missing from the half-hourly record 
of annual NEE were modeled by combining estimates of canopy photosynthesis and nocturnal respiration. Daytime $\mathrm{CO}_{2}$ exchange rates were obtained from Michaelis-Menten models of PPFD with coefficients fitted on a monthly basis. Missing nocturnal $\mathrm{CO}_{2}$ exchange values were obtained from second order Fourier regressions between Julian day and nocturnal respiration. Filled half-hourly NEE data were used to estimate respiration and GPP in the following way. All data points with PAR values $<5 \mu \mathrm{mol} \cdot \mathrm{m}^{-2}$. $\mathrm{s}^{-1}$ were used to estimate dark respiration rate. For each year, all dark NEE values were regressed against measured soil temperature using the relationship from (Lloyd and Taylor 1994). The resulting regression equation was then used with measured soil temperatures to predict respiration during light periods (PAR $>5 \mu \mathrm{mol} \cdot \mathrm{m}^{-2} \cdot \mathrm{s}^{-1}$ ). GPP was then estimated as NEE minus estimated respiration for all light periods, using convention of opposite signs for GPP and respiration (Hollinger et al. 2004).

A variety of meteorological measurements, including daily maximum temperature, daily minimum temperature $\left({ }^{\circ} \mathrm{C}\right)$, and daily sum of photosynthetically active radiation $\left(\mathrm{PAR}, \mathrm{mol} \cdot \mathrm{m}^{-2} \cdot \mathrm{d}^{-1}\right)$, are available for this study (Fig. 2). To better capture the effect of air temperature, in calculation of $T_{\text {scalar }}$ instead of using the daily mean air temperature that is calculated as the mean value between daily maximum temperature (daytime) and daily minimum temperature (nighttime), we used the mean daytime temperature, which was estimated as the mean between daily mean temperature and daily maximum temperature (Aber and Federer 1992). Daily PAR and mean daytime temperature data were then used for simulation of the VPM model with daily MODIS data.

In order to run the VPM model with eight-day MODIS data, both daily climate data (PAR and mean daytime temperature) and $\mathrm{CO}_{2}$ flux data were aggregated to eight-day intervals (consistent with the days of year used in MODIS eight-day composite data). The mean of daily daytime mean temperature and the sums of PAR and $\mathrm{CO}_{2}$ fluxes over eight-day periods were calculated, respectively (Fig. 2).

\section{Results}

\section{Seasonal dynamics of FAPAR, NDVI, and EVI from eight-day composites of MODIS}

Seasonal dynamics of FAPAR data from the standard eight-day MODIS LAI/FAPAR product shows little seasonal variations of FAPAR, and is similar to NDVI calculated from the MODIS pixel centered on the tower site in 2001-2002 in terms of phase and amplitude (Fig. 3 ). The standard MODIS eight-day LAI/FAPAR product employs a canopy radiative transfer model to estimate LAI and FAPAR (Knyazikhin et al. 1998), and if the radiative transfer model could not reach a stable solution, a backup NDVI-LAI-FAPAR algorithm is used. The LAI/FAPAR product provides a quality flag that indicates the success or failure of the radiative transfer model over the eight-day period. For instance, for the data presented in Fig. 3, 16 FAPAR periods in 2001 and 21 FAPAR periods in 2002 were derived from the radiative transfer model. Calculating FAPAR using the LAI of the Howland site (see Eq. 1, LAI $=5.3 \mathrm{~m}^{2} /$ $\left.\mathrm{m}^{2}, k=0.5\right)$, results in a FAPAR of $\sim 0.88$, which is similar to MODIS FAPAR in the summer (Fig. 3). The LAI/FAPAR data indicate that the canopy radiative transfer model and the empirical LAI-FAPAR-NDVI relationship work reasonably well for the evergreen needleleaf forest at the Howland site. The seasonal dynamics of NDVI suggest that FAPAR estimated by a function of NDVI is likely to represent the sum of

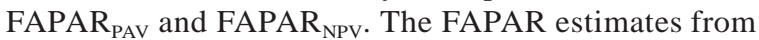
the radiative transfer modeling approach are also likely to represent the sum of FAPAR $\mathrm{PAV}$ and $\mathrm{FAPAR}_{\mathrm{NPV}}$.

Seasonal dynamics of EVI within the plant-growing season at the Howland site differ substantially from NDVI and FAPAR in terms of phase and magnitude (Fig. 3). The maximum EVI values in summer were 0.56 in 2001 and 0.62 in 2002, which were much lower than the maximum NDVI values (0.89 in 2001, 0.86 in 2002). While NDVI and FAPAR curves had a plateau during the summer, EVI changed significantly over time, reaching its peak in early summer and then declining gradually (Fig. 3). The temporal dynamics of EVI within the plant-growing season (April-November) is closely correlated to the dynamics of observed GPP at the Howland Forest tower sites in 2001 (Figs. 4 and 5). It is not clear what factors account for the remarkable difference between EVI and NDVI-FAPAR during the plant-growing season, but we suspect two factors may be important. One factor may be the saturation of NDVI at the canopy level, as the LAI at the Howland site is relatively high $\left(5.3 \mathrm{~m}^{2} / \mathrm{m}^{2}\right)$. EVI does not appear to be as saturated as NDVI. As a result, EVI is still sensitive to phenological changes in leaf and canopy. The other factor may be changes in PAV and NPV proportions within individual leaves (leaf level), associated with the aging process of leaves. Also note that EVI is affected significantly by snow cover under the forest canopy, as indicated by high EVI values during winter and early spring seasons (Figs. 3 and 4). While NDVI and EVI are complementary vegetation indices (Huete et al. 2002), the remarkable differences between NDVI and EVI during the photosynthetically active period (April-November) suggest that there is a need for further investigation through field observations and radiative transfer modeling at both leaf and canopy levels.

\section{Seasonal dynamics of LSWI from eight-day composites of MODIS}

The LSWI has distinct seasonal dynamics over the year (Fig. 4). High LSWI values in winter and early spring are attributed to snow cover on and under the forest canopy. Snow cover has very high reflectance 

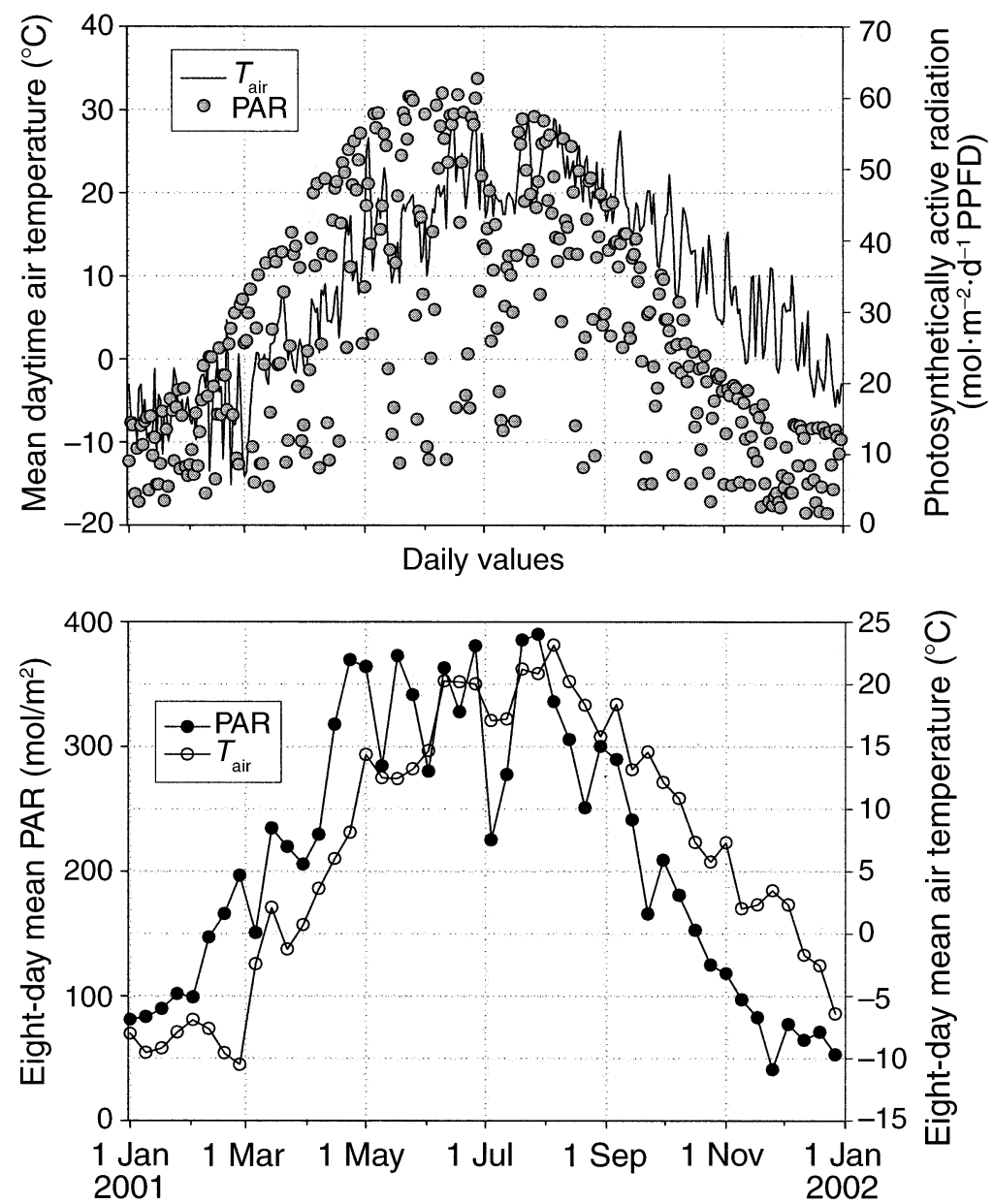

FIG. 2. The seasonal dynamics of air temperature and photosynthetically active radiation (PAR) in 2001 at the Howland Forest, Maine, USA. The flux tower site at Howland Forest is located at $45.20407^{\circ} \mathrm{N}$ and $68.74020^{\circ} \mathrm{W}$.

values in visible and NIR spectral bands but relatively low reflectance values in shortwave infrared (Xiao et al. 2002c). During the winter and early spring, the land surface is a mixture of vegetation and snow, which could result in high LSWI values. As spring progresses, air temperature increases and the snow cover gradually melts, resulting in a decline of LSWI values. It is interesting to note that LSWI increases again as the plant-

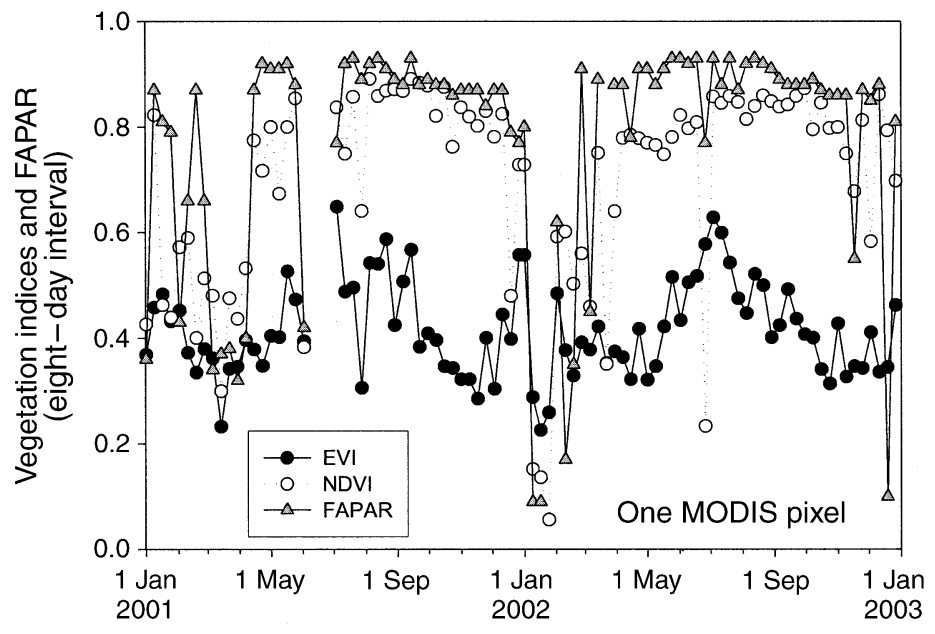

FIG. 3. The seasonal dynamics of enhanced vegetation index (EVI), normalized difference vegetation index (NDVI), and fraction of absorbed photosynthetically active radiation (FAPAR) over the period January 2001-December 2002 at the $\mathrm{CO}_{2}$ eddy flux tower site in Howland Forest, Maine. The flux tower site at Howland Forest is located at $45.20407^{\circ} \mathrm{N}$ and $68.74020^{\circ}$ W. The MODIS data used in this study are from the version 3 of MODIS standard products collection. NDVI and EVI are calculated from surface reflectance values from the standard MODIS eight-day composites (MOD09A1). FAPAR data are from the standard MODIS FAPAR/LAI product (MOD15A2). 

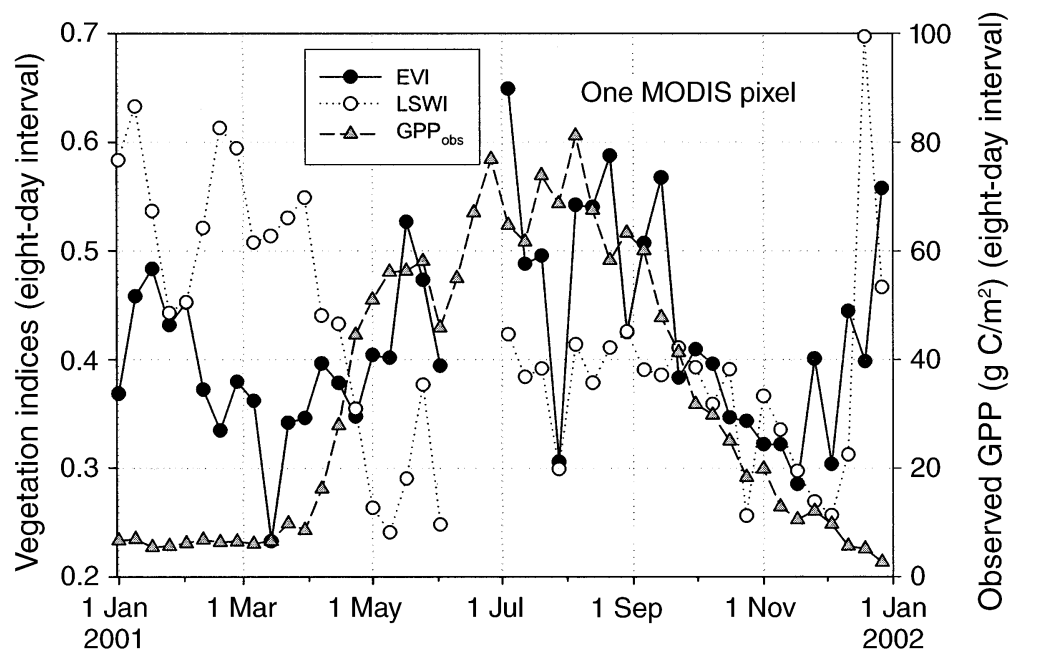

FIG. 4. The seasonal dynamics of improved vegetation indices and gross primary production (GPP) in 2001 at the eddy flux tower site in Howland Forest, Maine. The MODIS data set has three missing eight-day periods in June 2001. Key to abbreviations: EVI, enhanced vegetation index; LSWI, land surface water index.

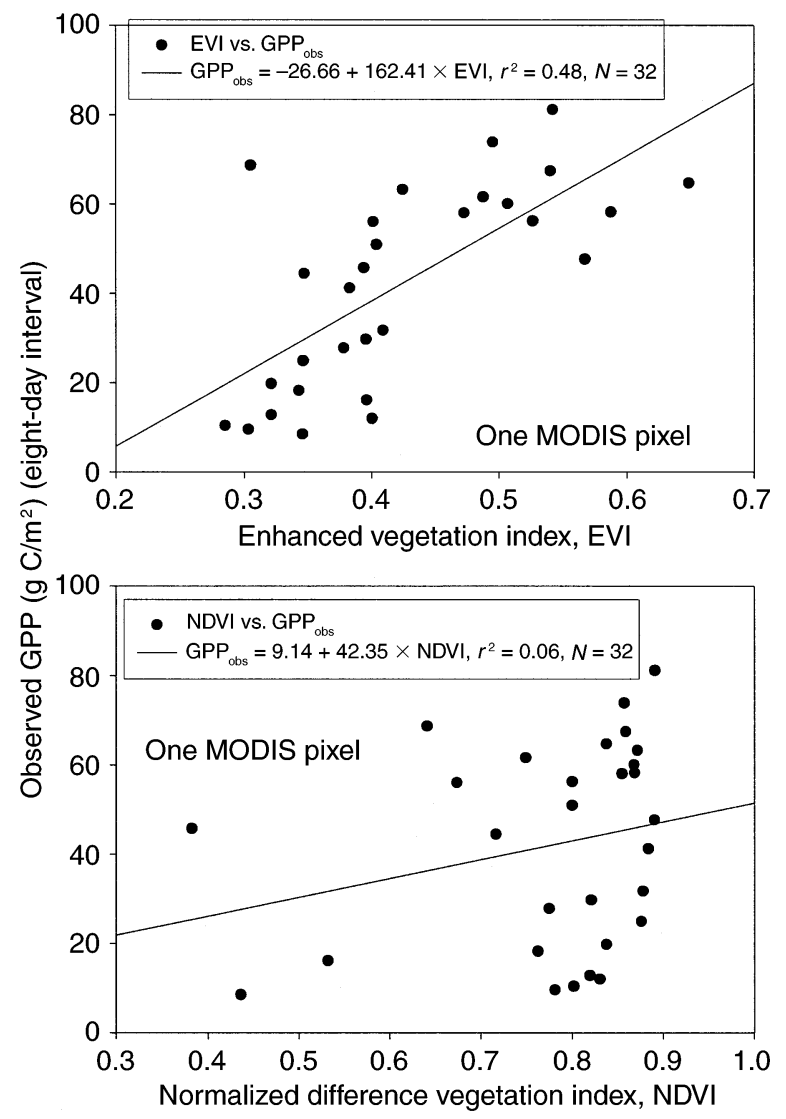

FIG. 5. The quantitative relationships between gross primary production (GPP) and vegetation indices in 2001 at the eddy flux tower site in Howland Forest, Maine. Data points in the graphs are 32 eight-day MODIS composites from 30 March-7 April 2001 to 3-10 December 2001. growing season progresses, and declined gradually in the late part of the plant-growing season (Fig. 4). As winter approaches, snow falls, and thus LSWI increased again. LSWI was highly correlated with MSI in 2001 (Fig. 6), as both LSWI and MSI indices use the same NIR and SWIR bands (see Eqs. 6, 7). The results from a modeling study that used the PROSPECT radiative transfer model confirmed the relationship between equivalent water content $\left(\mathrm{EWT}, \mathrm{g} / \mathrm{cm}^{2}\right)$ and the MSI, and suggested that MSI could therefore be used as a first approximation to retrieve vegetation water content at the leaf level (Ceccato et al. 2001). LSWI was also significantly correlated with NDWI in 2001 (Fig. 6), and NDWI was evaluated for retrieval of water content of leaf and canopy (Gao 1996, Serrano et al. 2000).

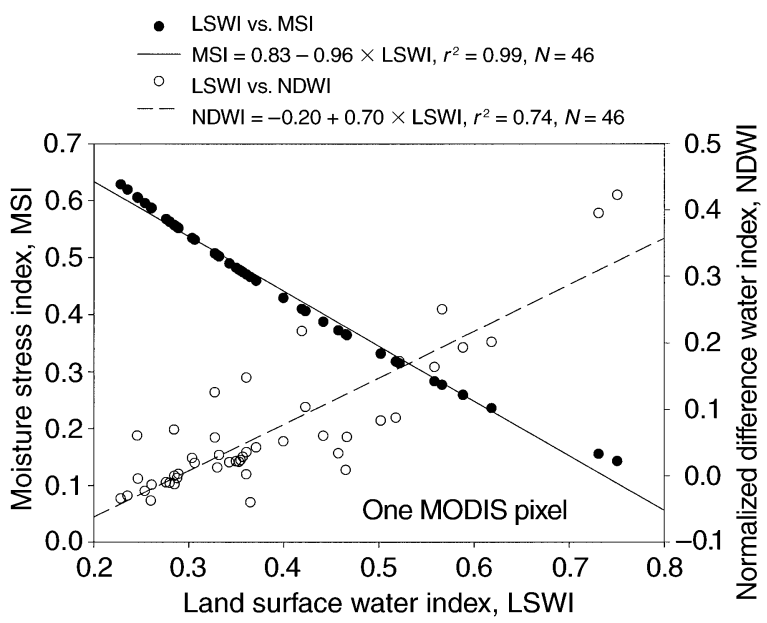

FIG. 6. Satellite-derived water-oriented vegetation indices from eight-day MODIS images in 2002 at the Howland site, Maine. 

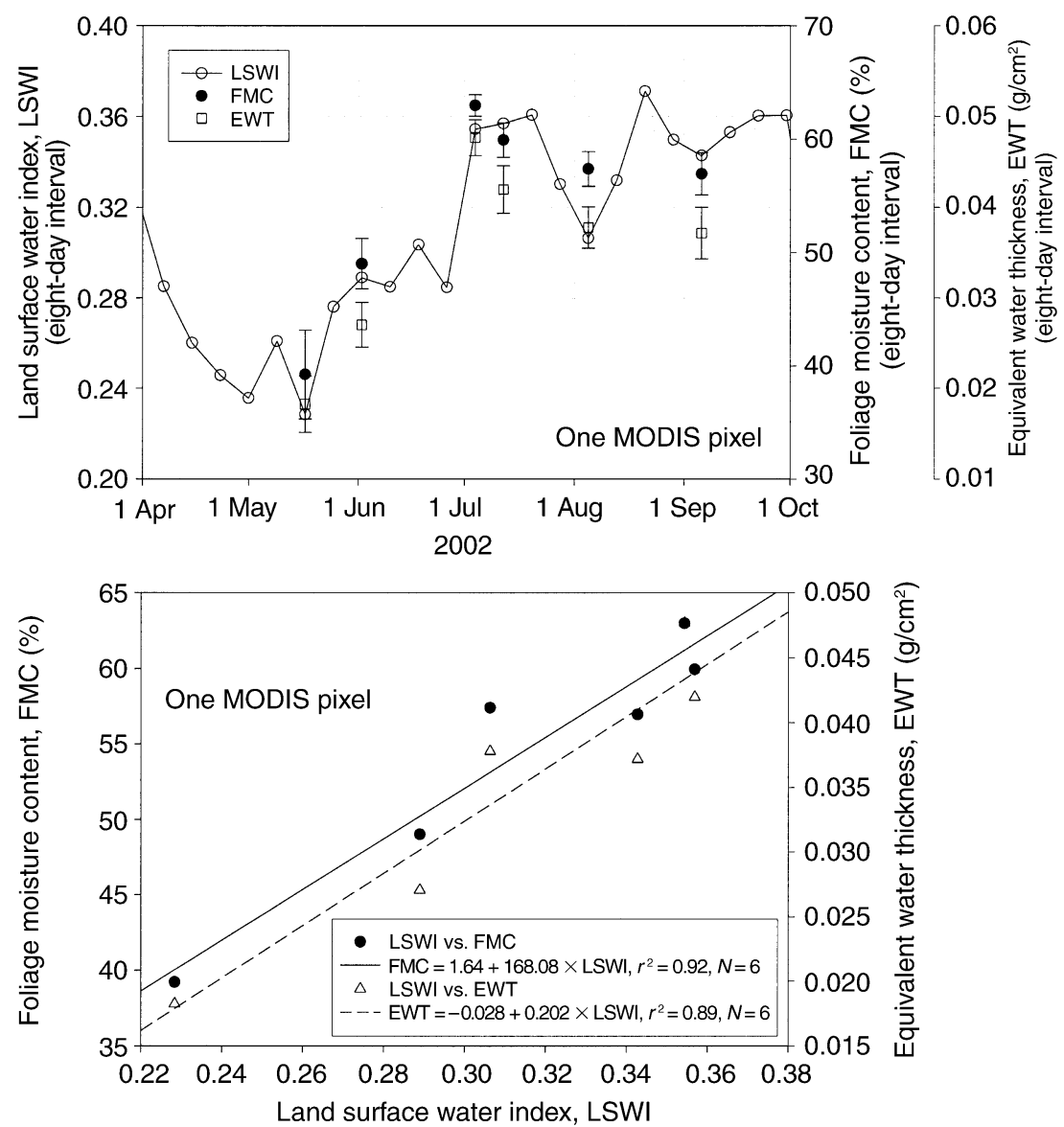

FIG. 7. A comparison of land surface water index (LSWI) and leaf water content of evergreen needleleaf forest in 2002 at Howland Forest, Maine. Error bars in the top panel are \pm SD.

During the plant-growing season (April-November) in 2002, LSWI continuously increased from May through midsummer (July), and had small variations throughout late summer (Fig. 7). It is not clear whether this is a response to total leaf area (biomass) or to leaf moisture content. Our assumption is that LSWI values in the plant-growing season are correlated to leaf and canopy water content. However, no large and systematically measured dataset of leaf and canopy water content of evergreen needleleaf forest are available to test the hypothesis. Here we report a very small dataset of leaf water content from the Howland site, with an aim to illustrate magnitude of changes in leaf water content of evergreen needleleaf forest. In a study unrelated to our effort in remote sensing, field sampling of spruce and hemlock needles was conducted at Howland Forest over six dates (19 May, 6 June, 9 and 16 July, 7 August, and 11 September) in 2002. On each sampling date, six samples of spruce and hemlock foliage were obtained. Samples were dried in electric oven for about one week at $60^{\circ} \mathrm{C}$. Fresh weight $(\mathrm{FW})$ and dry weight (DW) of spruce and hemlock needles were measured. Foliage moisture content (FMC, \%) at Howland Forest was calculated using fresh weight and dry weight as $\mathrm{FMC}=100 \times(\mathrm{FW}-\mathrm{DW}) / \mathrm{FW}$. Because no field measurements of specific leaf weight $\left(\mathrm{SLW}, \mathrm{g} / \mathrm{cm}^{2}\right)$ and leaf area index (LAI) were conducted on those sampling dates in 2002, we cannot accurately calculate equivalent water thickness $\left(\mathrm{EWT}, \mathrm{g} / \mathrm{m}^{2}\right.$ ) of the forest canopy on those sampling dates. However, unlike the grassland and savannah vegetation that have large seasonal changes in specific leaf weight (SLW) and LAI over the plant-growing season (Ceccato et al. 2002a), mature stands of evergreen needleleaf forests have only slightly changes in LAI and SLW over the plant-growing season, and therefore, single LAI and SLW values were often used in estimation of GPP of evergreen needleleaf forests by some process-based ecosystem models (Aber and Federer 1992, Law et al. 2000). As a simple approximation, we used LAI $=5.3 \mathrm{~m}^{2} / \mathrm{m}^{2}$ and $\mathrm{SLW}=280 \mathrm{~g} / \mathrm{m}^{2}$ (Aber and Federer 1992) to estimate EWT of evergreen needleleaf forest for the six sampling dates at Howland site (Fig. 7), and the resultant EWT varied from $0.018 \mathrm{~g} / \mathrm{cm}^{2}$ (19 May 2002) to 0.048 $\mathrm{g} / \mathrm{cm}^{2}$ (9 July 2002), within the EWT range reported in a study that examined the relationship between MSI 


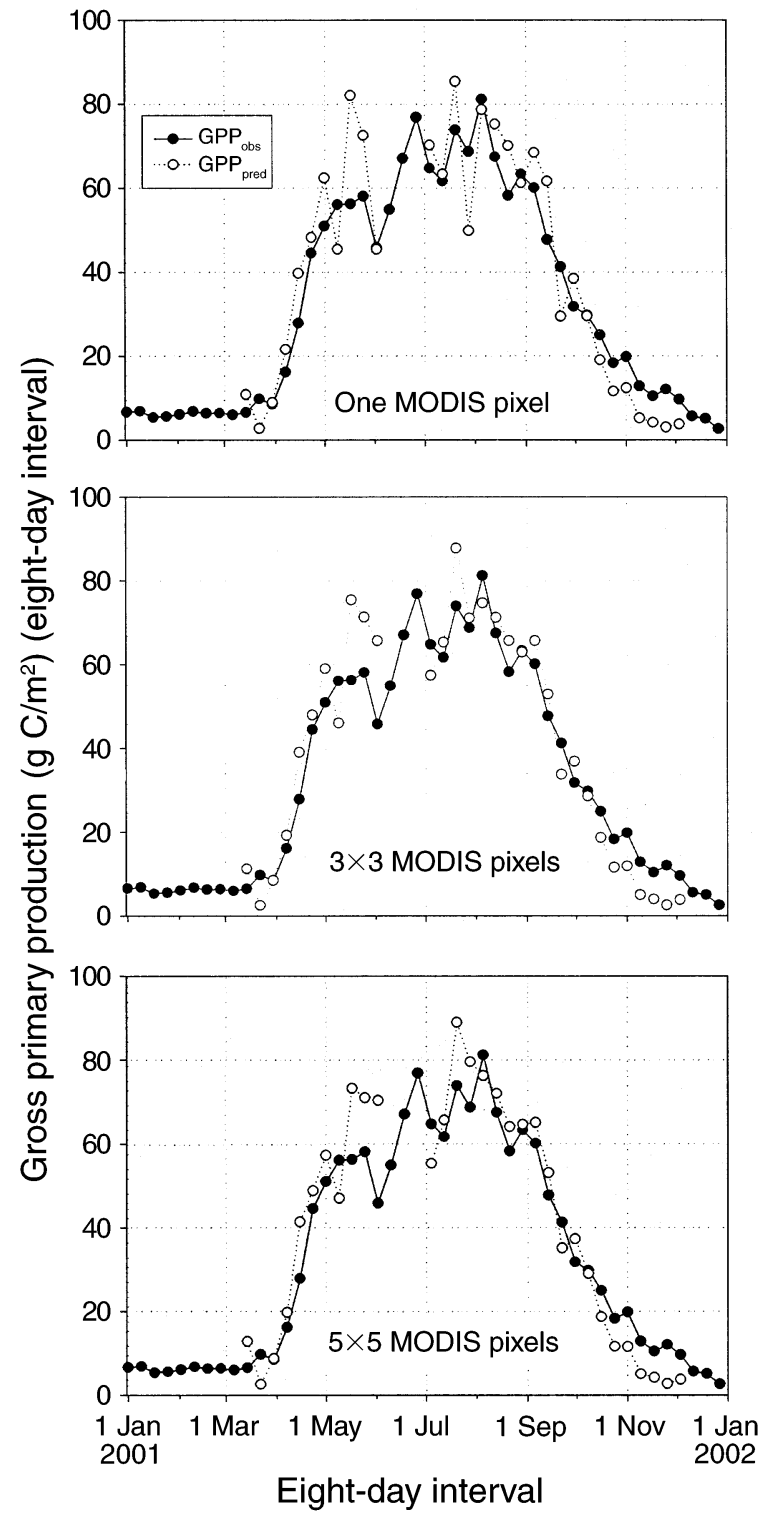

FIG. 8. Seasonal dynamics of gross primary production $\left(\mathrm{g} \mathrm{C} \cdot \mathrm{m}^{-2} \cdot[8 \mathrm{~d}]^{-1}\right)$ at the eddy flux tower site in Howland Forest, Maine, at (A) 1 , (B) $3 \times 3$, and (C) $5 \times 5$ MODIS pixels. The predicted GPP ( $\left(\mathrm{GPP}_{\text {pred }}\right)$ is from the VPM model, using eight-day MODIS composites. Observed GPP (GPP $\left.{ }_{\text {obs }}\right)$ is based on the half-hourly data of net ecosystem exchange (NEE) and ecosystem respiration in 2001 at the $\mathrm{CO}_{2}$ flux tower site.

and EWT (Ceccato et al. 2001). The limited field dataset shows that there were large changes in leaf water content over the plant-growing season at the Howland site (Fig. 7). The comparison between LSWI and leaf water content data indicates that the temporal dynamics of LSWI in 2002 were indicative of changes of FMC and EWT within the plant-growing season at the Howland site (Fig. 7). We recognize the complex scalingup issue from leaf-level measurement through canopy level to MODIS pixels (500 m spatial resolution). For future field work at the Howland site, additional field measurement of SLW and LAI should be carried out together with measurements of foliage fresh and dry weight, which would provide a large field dataset for improving retrieval of EWT through satellite-based water indices, as demonstrated in recent modeling and field studies (Ceccato et al. 2001, 2002a, b).

\section{Predicted gross primary production from eight-day composites of MODIS}

The seasonal dynamics of GPP simulated by the VPM model using the eight-day MODIS data and climate data from Howland agree reasonably well with the dynamics of observed GPP in 2001 from the $\mathrm{CO}_{2}$ flux tower site (Figs. 8 and 9). Predicted GPP from the $3 \times 3$ pixel block has slightly improved agreement with observed GPP, in comparison to predicted GPP from one MODIS pixel (center pixel of the $3 \times 3$ pixel block), particularly in the summer of 2001. Predicted GPP values from the $5 \times 5$ pixel block are not significantly different from predicted GPP based on the $3 \times$ 3 pixel block. As shown in Fig. 10, the study area is relatively homogeneous from one pixel $(500 \mathrm{~m})$ to the $5 \times 5$ pixel block $(2.5 \mathrm{~km}$ wide $)$. This indicates that the eddy flux tower at the Howland site is representative of the surrounding area. The good agreement between

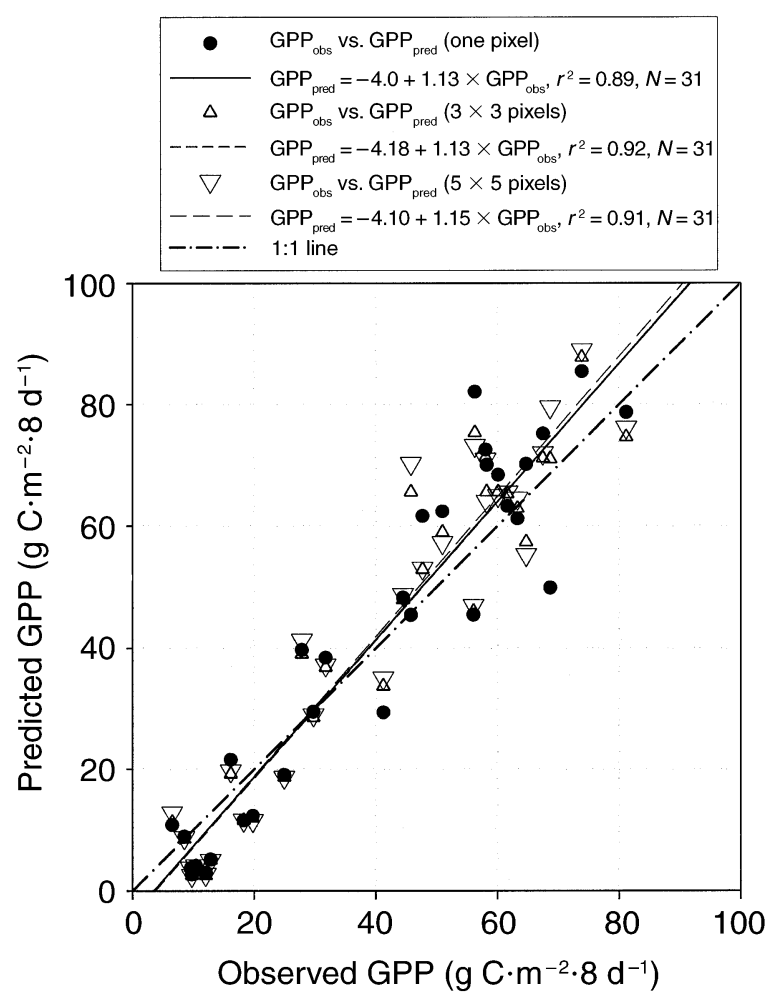

FIG. 9. A linear comparison between predicted and observed gross primary production during the period of 14 March-10 December 2001 at the $\mathrm{CO}_{2}$ eddy flux tower site in Howland Forest, Maine. Predicted GPP values are from simulations of VPM using eight-day MODIS composites. 

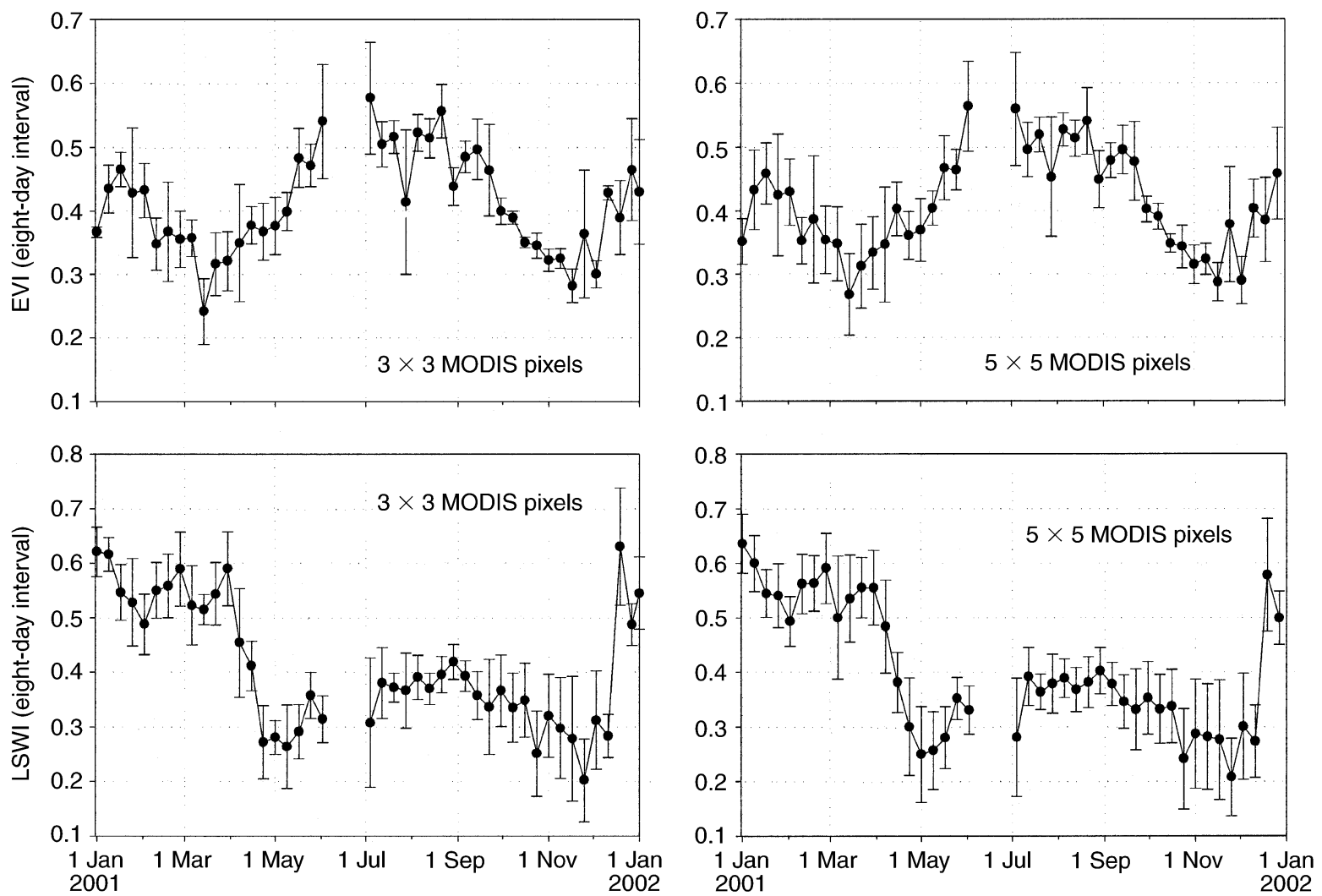

FIG. 10. Enhanced vegetation index (EVI; top panels) and land surface water index (LSWI; bottom panels) within a 3 $\times 3$ pixel kernel and a $5 \times 5$ pixel kernel of MODIS data for the Howland site, Maine. Values are means \pm SD.

$\mathrm{GPP}_{\text {pred }}$ and $\mathrm{GPP}_{\text {obs }}$ over the plant-growing season (Figs. 8 and 9) provides indirect evidence to support the hypothesis that EVI is linearly correlated to FAPAR PAV $_{\text {. }}$ Seasonally integrated $\mathrm{GPP}_{\text {pred }}$ values over the period 30 March to 10 December 2001 (Fig. 9) were 1280, 1277, $1296 \mathrm{~g} \mathrm{C} / \mathrm{m}^{2}$ for 1 pixel, the $3 \times 3$ pixel block, and the $5 \times 5$ pixel block, respectively, which were, respectively, $\sim 3 \%, 3 \%$, and $5 \%$ higher than the seasonally integrated $\mathrm{GPP}_{\mathrm{obs}}$ for the same set of eight-day observations (1238 $\mathrm{g} \mathrm{C}^{2} \mathrm{~m}^{2}$ ). The seasonal dynamic of EVI may reflect changes in leaf biophysical (increase in leaf weight and thickness) and/or biochemical properties (foliage nitrogen or chlorophyll content) associated with leaf age. Further studies are needed to correlate EVI with biochemical properties of forests over space and time.

\section{Seasonal dynamics of EVI and LSWI from daily MODIS data}

There were large variations in EVI and LSWI values from daily MODIS data in 2001 (Fig. 11), which clearly reflects the impacts of clouds on reflectance values and vegetation indices. Reflectance values in blue band are indicative of clouds and aerosols in the atmosphere. For simplification, we applied a threshold of blue band $(\geq 0.20)$ to exclude those observations that were potentially affected by clouds and aerosols, and the re- maining observations of EVI and LSWI in 2001 have a clear pattern of seasonality (Fig. 11).

The VPM model was run using daily climate data (temperature, PAR) from the Howland tower site (see Fig. 2) and the "clean" observations of EVI and LSWI (with a reflectance threshold of blue band $<0.20$ ) from the daily MODIS images (Fig. 11). The predicted daily GPP values agree reasonably well with observed daily GPP of evergreen needleleaf forest at the Howland site (Figs. 12 and 13). The sum of 149 daily GPP pred values (see Fig. 13) was $695 \mathrm{~g} \mathrm{C} / \mathrm{m}^{2}$, while the sum of 149 daily $\mathrm{GPP}_{\text {obs }}$ was $845 \mathrm{~g} \mathrm{C} / \mathrm{m}^{2}$, a difference of $22 \%$ between $\mathrm{GPP}_{\text {pred }}$ and $\mathrm{GPP}_{\text {obs }}$.

\section{DISCUSSION}

The results from simulations of the VPM model using both daily MODIS data and eight-day composite MODIS data have shown that the VPM model predicts reasonably well the gross primary production of an evergreen needleleaf forest. Note that the performance of the VPM model varies between eight-day MODIS composites and daily MODIS image. The VPM model overestimated GPP when using eight-day MODIS composites, but underestimated GPP when using daily MODIS composites, as indicated by the slopes of simple linear regression models between VPM-predicted GPP and observed GPP from the flux tower site (Figs. 


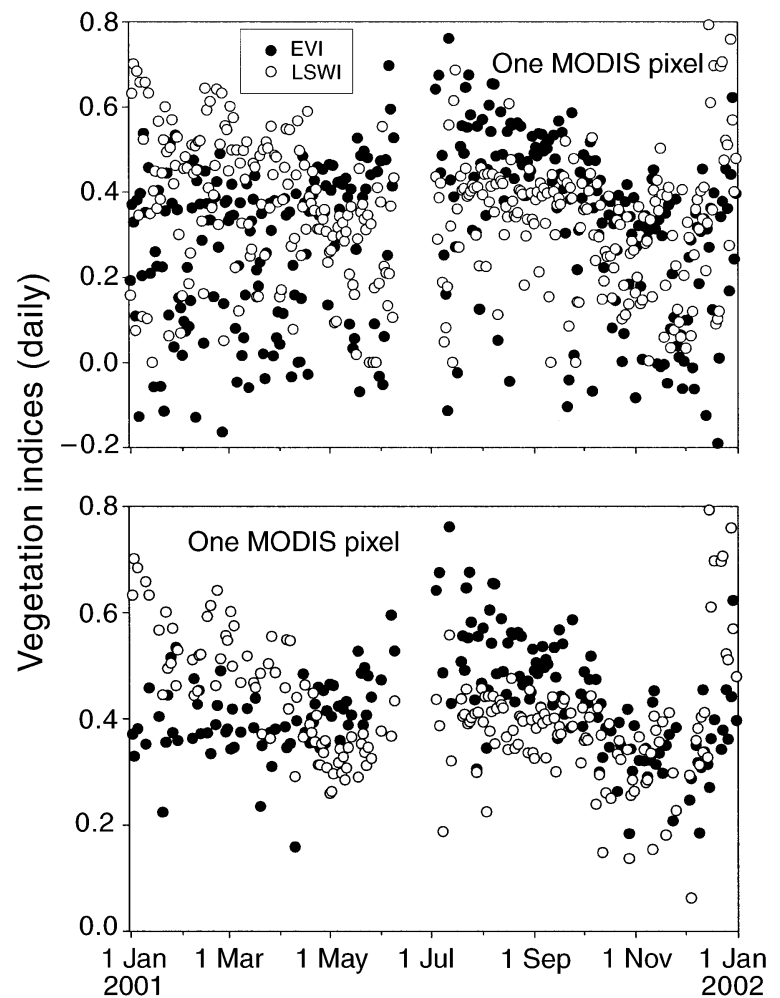

FIG. 11. The seasonal dynamics of enhanced vegetation index (EVI) and land surface water index (LSWI) from daily MODIS data in 2001 at the Howland site, Maine. The upper panel includes all observations in a year, and the lower panel includes only those observations (193) with reflectance values of blue band $(<0.20)$.

9 and 13). Seasonally integrated $\mathrm{GPP}_{\text {pred }}$ (from eightday MODIS composites) was only slightly larger $(\sim 3 \%)$ than seasonally integrated $\mathrm{GPP}_{\mathrm{obs}}$. Seasonally integrated $\mathrm{GPP}_{\text {pred }}$ (from daily MODIS images, 149 days) was lower than $(\sim 22 \%)$ seasonally integrated $\mathrm{GPP}_{\text {obs }}$. Performance of all models depends upon input data. For the VPM model, it is largely vegetation indices from eight-day or daily MODIS imagery that affect performance of VPM, as temperature and PAR data are the same for both daily and eight-day simulations of VPM. In general, daily MODIS images are frequently affected by atmospheric condition, which could result in lower values of vegetation indices (e.g., NDVI, EVI, and LSWI). The results of this study suggest that eight-day MODIS composites would be a better input dataset than daily MODIS images. This is largely attributed to the methods used in generating eight-day MODIS composites: selecting an observation with maximum NDVI value (likely to be a most clear observation) over an eight-day period. Given the fact that leaf and canopy condition (e.g., PAV) does not change significantly at a daily timestep, it is reasonable to select an observation with a maximum vegetation index (e.g., NDVI) value and the least atmospheric contamination over a period of a few days (in this case,

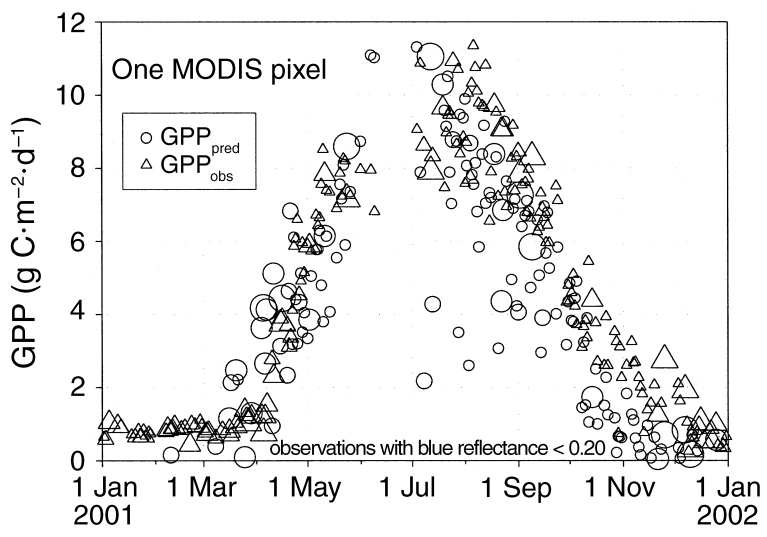

FIG. 12. A comparison of the seasonal dynamics of daily

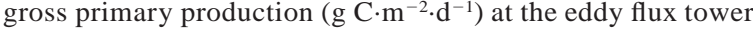
site in Howland Forest, Maine. The predicted GPP $\left(\mathrm{GPP}_{\text {pred }}\right)$ is from the VPM model, and observed GPP $\left(\mathrm{GPP}_{\mathrm{obs}}\right)$ is based on the half-hourly data of net ecosystem exchange (NEE) and ecosystem respiration in 2001 at the $\mathrm{CO}_{2}$ flux tower site. The size of symbol in the graph is related to reflectance values of blue band: the larger the size of symbol, the higher are the reflectance values of blue band.

eight-day for MODIS composites). From the purpose of practical application at large spatial scales, using eight-day MODIS composites as input data for the VPM model is also a better choice, as it avoids storage of the large volume of daily MODIS images and requires less computer time.

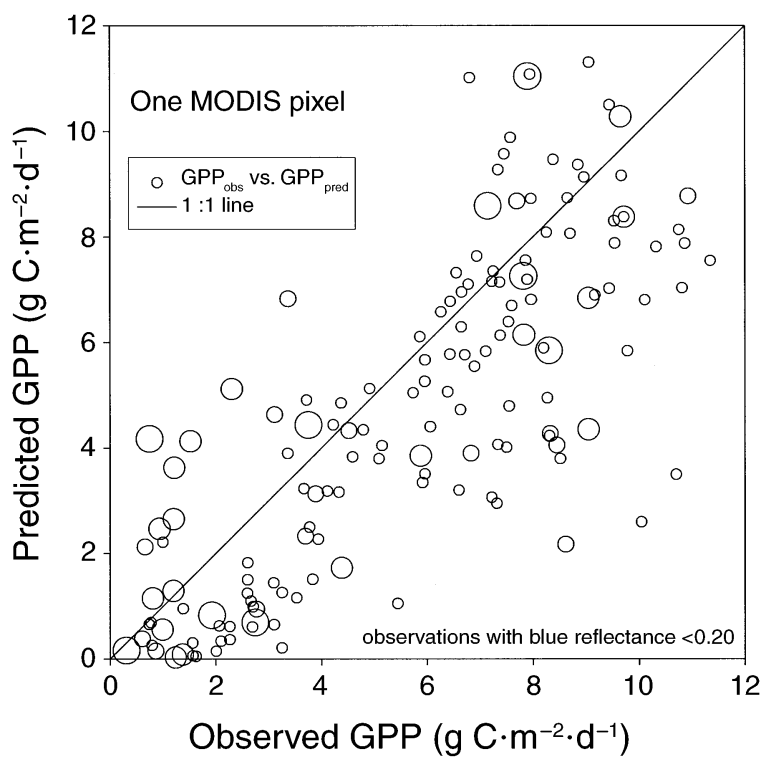

FIG. 13. A linear comparison of predicted and observed daily gross primary production $\left(\mathrm{g} \mathrm{C} \cdot \mathrm{m}^{-2} \cdot \mathrm{d}^{-1}\right)$ at the eddy flux tower site in Howland Forest, Maine. The size of symbol in the graph is related to reflectance values of blue band: the larger the size of symbol, the higher are the reflectance values of blue band. The linear regression model between $\mathrm{GPP}_{\text {pred }}$ and $\mathrm{GPP}_{\mathrm{obs}}$ is the following: $\mathrm{GPP}_{\text {pred }}=0.17+0.79 \times \mathrm{GPP}_{\mathrm{ob}}$, $r^{2}=0.61, N=149 ; \mathrm{GPP}_{\text {pred }}=0.82 \times \mathrm{GPP}_{\mathrm{obs}}, r^{2}=0.61, N$ $=149$. 
In comparison to other PEM models that employ only NDVI (Prince and Goward 1995, Ruimy et al. 1996, Running et al. 1999, 2000), the VPM model has two simple but innovative features. The first feature is that the VPM model uses an improved vegetation index that is related to vegetation greenness (e.g., EVI in this study) to estimate FAPAR $\mathrm{PAV}_{\text {. The second feature is }}$ that the VPM model uses an improved vegetation index that is related to vegetation water content (e.g., LSWI in this study) to estimate the effect of water on photosynthesis. One advantage of using water-related vegetation index in the VPM model is that there is no need for a soil moisture model that is usually driven by very coarse resolution of input datasets (e.g., precipitation, soil texture, and soil depth), which could result in large uncertainty or error in soil moisture. There exist a few water-oriented vegetation indices (Hunt and Rock 1989, Gao 1996, Ceccato et al. 2002a, b, Xiao et al. 2002a, Maki et al. 2004), and extensive field work is needed to collect seasonal data of leaf and canopy water content, which would help evaluate those spectral water indices and improve understanding of water-related biophysical processes of leaves over time. In addition, a comparison between water-related vegetation index and soil moisture data from a soil moisture model should be conducted. Although these two innovative features need to be validated across various biomes through systematic and extensive field measurement and radiative transfer modeling, the VPM model has the potential to improve estimation of seasonal dynamics and interannual variations of gross primary production of forests, in comparison to the other existing PEM models that employ NDVI only.

In the VPM model, the conceptual partitioning of FAPAR into FAPAR PAV $_{\text {F }}$ and FAR $_{\mathrm{NPV}}$ is proposed and implemented. The differences between FAPAR (or NDVI) and EVI values were relatively large in the early and late growing season of evergreen needleleaf forests (Fig. 3). If the FAPAR values (Fig. 3) were directly used in the other PEM models (Table 1), the resultant FAPAR $\times$ PAR product will be substantially larger than the FAPAR $_{\mathrm{PAV}} \times$ PAR product in the VPM model, which could lead to overestimation of GPP in the other PEM models, especially during the early and late growing season of forests, as the seasonal dynamics of FAPAR is not in phase with GPP over the year (Fig. 4). In a similar fashion, some process-based GPP/NPP models scale up (integrate) leaf photosynthesis to canopy photosynthesis through LAI without a partitioning of PAV and NPV in the forest canopy, which are likely to overestimate GPP and NPP, particularly in the early and late growing season of forests. In a study that estimated large-scale $\mathrm{CO}_{2}$ fluxes in high latitudes from four process-based terrestrial biosphere models (TBMs) and an inversion of atmospheric $\mathrm{CO}_{2}$ measurement (Dargaville et al. 2002), the results showed that the four TBMs overestimated carbon uptake from the atmosphere in the early part of the year. Note that in this study, we only highlighted the importance and potential of partitioning of FAPAR into FAPAR PAV $_{\text {and }}$ $\mathrm{FAPAR}_{\mathrm{NPV}}$. Additional field sampling and radiative transfer modeling activities are critically needed to better quantify seasonally dynamics of PAV and NPV as well as FAPAR PAV $_{\text {and FAPAR }}$ NPV.

For all the PEM models (Fig. 1, Table 1), the mathematic formulae can be reduced to

$$
\mathrm{GPP}=\varepsilon_{\mathrm{g}} \times \mathrm{PAR}_{\mathrm{abs}}
$$

where PAR $_{a b s}$ is the product of either FAPAR $\times$ PAR or FAPAR $_{\mathrm{PAV}} \times$ PAR. Adjusting either $\varepsilon_{\mathrm{g}}$ or $\mathrm{PAR}_{\mathrm{abs}}$ could result in similar GPP predictions. As shown in Table 1, the PEM models differ in model parameter $\left(\varepsilon_{0}\right)$. Estimation of the $\varepsilon_{0}$ parameter is largely determined by the choice of either a linear or nonlinear model (e.g., hyperbolic equation) between GPP and incident photosynthetic photon flux density (PPFD) data (generally at half-hour timestep) over a year (Ruimy et al. 1995, 1996, Frolking et al. 1998). In the terrestrial uptake and release of carbon (TURC) model, Ruimy et al. (1996) used $\varepsilon_{0}=0.020 \mu \mathrm{mol} \mathrm{CO} 2 / \mu \mathrm{mol}$ PAR (0.24 g C/mol PAR) for forests. In the GLO-PEM model, $\varepsilon_{\mathrm{g}}$ is modeled as a function of $\varepsilon_{0}$, temperature, vapor pressure deficit (VPD), and soil moisture (Prince and Goward 1995). The mean $\varepsilon_{0}$ of evergreen needleleaf forest in the GLO-PEM model is $0.66 \mathrm{~g} \mathrm{C} / \mathrm{MJ}$, or $\sim 0.14 \mathrm{~g} \mathrm{C} / \mathrm{mol}$ PAR (Prince and Goward 1995). In the MODIS GPP/NPP algorithm, $\varepsilon_{\mathrm{g}}$ is modeled as a function of $\varepsilon_{0}$, temperature and vapor pressure deficit (Running et al. 1999, 2000). The $\varepsilon_{0}$ value for evergreen needleleaf forest in the GPP algorithm of MODIS standard product (MOD17; Running et al. 1999, 2000) is $1.008 \mathrm{~g} \mathrm{C} / \mathrm{MJ}$ ( $\sim 0.22 \mathrm{~g} \mathrm{C} / \mathrm{mol}$ PAR), much lower than the $0.48 \mathrm{~g} \mathrm{C} / \mathrm{mol}$ PAR used here from a boreal forest tower site in Canada (Goulden et al. 1997), based on an approximate conversion between MJ PAR $\left(10^{6}\right.$ joules) and mol PAR of 4.6 (Weiss and Norman 1985, Aber et al. 1996). For the three-PG model (Law et al. 2000) that uses LAI and NDVI to estimate FAPAR and consequently has large $\mathrm{PAR}_{\mathrm{abs}}$ values, $\varepsilon_{\mathrm{g}}$ has to be down-regulated substantially (up to a factor of 2) through such environmental factors as temperature and vapor pressure deficit, in order for predicted GPP to match the observed GPP of evergreen needleleaf forest over the growing season.

It is important to note that the VPM model has only one free parameter $\left(\varepsilon_{0}\right)$ that is biome specific. For boreal evergreen needleleaf forest, we did use $\varepsilon_{0}$ value from a boreal forest flux tower site in Canada (Goulden et al. 1997). Application of the VPM model to other biomes requires estimation of the parameter $\left(\varepsilon_{0}\right)$ for individual biomes, and estimated values of parameter $\left(\varepsilon_{0}\right)$ can be found in publications from $\mathrm{CO}_{2}$ flux tower sites (e.g., Wofsy et al. 1993, Goulden et al. 1997). At present, over two hundred $\mathrm{CO}_{2}$ eddy flux tower sites across various biomes in the world are operating on a long-term and continuous basis, as part of the global 
FLUXNET program (available online). ${ }^{6}$ These flux tower sites provide valuable information on $\mathrm{CO}_{2}$ and PAR fluxes at ecosystem to landscape levels, as well as estimation of parameter $\left(\varepsilon_{0}\right)$. Uncertainty of model parameter $\left(\varepsilon_{0}\right)$ in existing PEM models and the VPM model needs to be quantified within a biome and across biomes. Information from the $\mathrm{CO}_{2}$ flux network can be used to quantify uncertainties of the $\varepsilon_{0}$ parameter and $\varepsilon_{\mathrm{g}}$ across biomes and within a biome.

In summary, we have developed and validate a satellite-based vegetation photosynthesis model (VPM) that incorporates improved vegetation indices derived from a new generation of advanced optical sensors. Simulations of the VPM model were conducted at both daily and eight-day intervals, using both daily and eight-day composite MODIS data, respectively. The results have demonstrated the potential of MODIS data and the VPM model for estimating GPP of evergreen needleleaf forests at daily and eight-day intervals. The satellite-based VPM model, which is even simpler than other global PEM models (Prince and Goward 1995, Running et al. 2000), has the potential to provide estimates of gross primary production of forests at large spatial scales. In addition, the VPM model could be coupled with other biogeochemical models that estimate ecosystem respiration; when used in a diagnostic mode, the coupled models have the potential to provide more accurate estimates of net primary production and net ecosystem production of forests, and lead to improved understanding of the magnitude, geographical variation, and mechanisms of $\mathrm{CO}_{2}$ uptake by the terrestrial biosphere.

\section{ACKNOWLEDGMENTS}

We thank the International Paper Company, for providing access to the research site in Howland, Maine. John Lee, Holly Hughes, and Jeremiah Walsh provided expert assistance with the Howland Forest multi-year $\mathrm{CO}_{2}$ flux and climate data set. We thank the anonymous reviewers for their comments and suggestions on earlier versions of the manuscript. The Howland flux research was supported by the Office of Science (BER), U.S. Department of Energy, through the Northeast Regional Center of the National Institute for Global Environmental Change under Cooperative Agreement No. DEFC03-90ER61010 and by the Office of Science (BER), U.S. Department of Energy Interagency Agreement No. DE-AI0200ER63028. The modeling study was supported by research grants from NASA Interdisciplinary Science Program (NAG5-10135) and Land Cover and Land Use Change Program (NAG5-11160).

\section{Literature Cited}

Aber, J. D., and C. A. Federer. 1992. A generalized, lumpedparameter model of photosynthesis, evapotranspiration and net primary production in temperate and boreal forest ecosystems. Oecologia 92:463-474.

Aber, J. D., P. B. Reich, and M. L. Goulden. 1996. Extrapolating leaf $\mathrm{CO}_{2}$ exchange to the canopy: a generalized model of forest photosynthesis compared with measurements by eddy correlation. Oecologia 106:257-265.

Asner, G. P., C. A. Wessman, and S. Archer. 1998. Scale dependence of absorption of photosynthetically active ra-

\footnotetext{
${ }^{6}\langle$ http://www.daac.ornl.gov/FLUXNET/fluxnet.html $\rangle$
}

diation in terrestrial ecosystems. Ecological Applications 8:1003-1021.

Barford, C. C., S. C. Wofsy, M. L. Goulden, J. W. Munger, E. H. Pyle, S. P. Urbanski, L. Hutyra, S. R. Saleska, D. Fitzjarrald, and K. Moore. 2001. Factors controlling longand short-term sequestration of atmospheric $\mathrm{CO}_{2}$ in a midlatitude forest. Science 294:1688-1691.

Ceccato, P., S. Flasse, and J. M. Gregoire. 2002a. Designing a spectral index to estimate vegetation water content from remote sensing data: part 2, validation and applications. Remote Sensing of Environment 82:198-207.

Ceccato, P., S. Flasse, S. Tarantola, S. Jacquemoud, and J. M. Gregoire. 2001. Detecting vegetation leaf water content using reflectance in the optical domain. Remote Sensing of Environment 77:22-33.

Ceccato, P., N. Gobron, S. Flasse, B. Pinty, and S. Tarantola. $2002 b$. Designing a spectral index to estimate vegetation water content from remote sensing data: part 1, theoretical approach. Remote Sensing of Environment 82:188-197.

Dargaville, R., A. D. McGuire, and P. Rayner. 2002. Estimates of large-scale fluxes in high latitudes from terrestrial biosphere models and an inversion of atmospheric $\mathrm{CO}_{2}$ measurements. Climatic Change 55:273-285.

Field, C. B., J. T. Randerson, and C. M. Malmstrom. 1995. Global net primary production-combining ecology and remote-sensing. Remote Sensing of Environment 51:7488.

Frolking, S. E., J. L. Bubier, T. R. Moore, T. Ball, L. M. Bellisario, A. Bhardwaj, P. Carroll, P. M. Crill, P. M. Lafleur, J. H. McCaughey, N. T. Roulet, A. E. Suyker, et al. 1998. Relationship between ecosystem productivity and photosynthetically active radiation for northern peatlands. Global Biogeochemical Cycles 12:115-126.

Gao, B. C. 1996. NDWI: a normalized difference water index for remote sensing of vegetation liquid water from space. Remote Sensing of Environment 58:257-266.

Gobron, N., B. Pinty, M. M. Verstraete, and J. L. Widlowski. 2000. Advanced vegetation indices optimized for up-coming sensors: design, performance, and applications. IEEE Transactions on Geoscience and Remote Sensing 38:24892505.

Goulden, M. L., B. C. Daube, S. M. Fan, D. J. Sutton, A. Bazzaz, J. W. Munger, and S. C. Wofsy. 1997. Physiological responses of a black spruce forest to weather. Journal of Geophysical Research: Atmospheres 102:28987-28996.

Govaerts, Y. M., M. M. Verstraete, B. Pinty, and N. Gobron. 1999. Designing optimal spectral indices: a feasibility and proof of concept study. International Journal of Remote Sensing 20:1853-1873.

Hanan, N. P., G. Burba, S. Verma, B. J. A. Berry, A. Suyker, and E. A. Walter-Shea. 2002. Inversion of net ecosystem $\mathrm{CO}_{2}$ flux measurements for estimation of canopy PAR absorption. Global Change Biology 8:563-574.

Hanan, N., P. Kabat, A. J. Dolman, and J. A. Elbers. 1998. Photosynthesis and carbon balance of a Sahelian fallow savanna. Global Change Biology 4:523-538.

Hollinger, D., J. Aber, B. Dail, E. A. Davidson, S. M. Goltz, H. Hughes, M. Y. Leclerc, J. T. Lee, A. D. Richardson, C. Rodrigues, N. A. Scott, D. Achuatavarier, and J. Walsh. 2004. Spatial and temporal variability in forest-atmosphere $\mathrm{CO}_{2}$ exchange. Global Change Biology 10:1-8.

Hollinger, D. Y., S. M. Goltz, E. A. Davidson, J. T. Lee, K. Tu, and H. T. Valentine. 1999. Seasonal patterns and environmental control of carbon dioxide and water vapour exchange in an ecotonal boreal forest. Global Change Biology 5:891-902.

Huete, A., K. Didan, T. Miura, E. P. Rodriguez, X. Gao, and 
L. G. Ferreira. 2002. Overview of the radiometric and biophysical performance of the MODIS vegetation indices. Remote Sensing of Environment 83:195-213.

Huete, A. R., H. Q. Liu, K. Batchily, and W. vanLeeuwen. 1997. A comparison of vegetation indices global set of TM images for EOS-MODIS. Remote Sensing of Environment 59:440-451.

Hunt, E. R., and B. N. Rock. 1989. Detection of changes in leaf water-content using near-infrared and middle-infrared reflectances. Remote Sensing of Environment 30:43-54.

Hunt, E. R., B. N. Rock, and P. S. Nobel. 1987. Measurement of leaf relative water-content by infrared reflectance. Remote Sensing of Environment 22:429-435.

Justice, C. O., E. Vermote, J. R. G. Townshend, R. Defries, D. P. Roy, D. K. Hall, V. V. Salomonson, J. L. Privette, G. Riggs, A. Strahler, W. Lucht, R. B. Myneni, et al. 1998. The moderate resolution imaging spectroradiometer (MODIS): land remote sensing for global change research. IEEE Transactions on Geoscience and Remote Sensing 36: $1228-1249$

Knyazikhin, Y., J. V. Martonchik, R. B. Myneni, D. J. Diner, and S. W. Running. 1998. Synergistic algorithm for estimating vegetation canopy leaf area index and fraction of absorbed photosynthetically active radiation from MODIS and MISR data. Journal of Geophysical Research-Atmospheres 103:32257-32275.

Lambers, H., F. S. Chapin, and T. L. Pons. 1998. Plant physiological ecology. Springer-Verlag, New York, New York, USA.

Law, B. E., R. H. Waring, P. M. Anthoni, and J. D. Aber. 2000. Measurements of gross and net ecosystem productivity and water vapour exchange of a Pinus ponderosa ecosystem, and an evaluation of two generalized models. Global Change Biology 6:155-168.

Lloyd, J., and J. A. Taylor. 1994. On the temperature dependence of soil respiration. Functional Ecology 8:315323.

Maki, M., M. Ishiahra, and M. Tamura. 2004. Estimation of leaf water status to monitor the risk of forest fires by using remotely sensed data. Remote Sensing of Environment 90: 441-450.

Malmstrom, C. M., M. V. Thompson, G. P. Juday, S. O. Los, J. T. Randerson, and C. B. Field. 1997. Interannual variation in global-scale net primary production: testing model estimates. Global Biogeochemical Cycles 11:367-392.

Myneni, R. B., S. Hoffman, Y. Knyazikhin, J. L. Privette, J. Glassy, Y. Tian, Y. Wang, X. Song, Y. Zhang, G. R. Smith, A. Lotsch, M. Friedl, et al. 2002. Global products of vegetation leaf area and fraction absorbed PAR from year one of MODIS data. Remote Sensing of Environment 83:214231.

Myneni, R. B., and D. L. Williams. 1994. On the relationship between FAPAR and NDVI. Remote Sensing of Environment 49:200-211.

Potter, C. S., J. T. Randerson, C. B. Field, P. A. Matson, P. M. Vitousek, H. A. Mooney, and S. A. Klooster. 1993. Terrestrial ecosystem production: a process model-based on global satellite and surface data. Global Biogeochemical Cycles 7:811-841.

Prince, S. D., and S. N. Goward. 1995. Global primary production: a remote sensing approach. Journal of Biogeography 22:815-835.

Raich, J. W., E. B. Rastetter, J. M. Melillo, D. W. Kicklighter, P. A. Steudler, B. J. Peterson, A. L. Grace, B. Moore, and C. J. Vorosmarty. 1991. Potential net primary productivity in South America: application of a global model. Ecological Applications 1:399-429.

Roberts, D. A., P. E. Dennison, M. E. Gardner, Y. Hetzel, S. L. Ustin, and C. T. Lee. 2003. Evaluation of the potential of Hyperion for fire danger assessment by comparison to the airborne visible/infrared imaging spectrometer. IEEE Transactions on Geoscience and Remote Sensing 41:12971310.

Ruimy, A., G. Dedieu, and B. Saugier. 1996. TURC: a diagnostic model of continental gross primary productivity and net primary productivity. Global Biogeochemical $\mathrm{Cy}-$ cles 10:269-285.

Ruimy, A., P. G. Jarvis, D. D. Baldocchi, and B. Saugier. 1995. $\mathrm{CO}_{2}$ fluxes over plant canopies and solar radiation: a review. Advances in Ecological Research 26:1-68.

Ruimy, A., L. Kergoat, and A. Bondeau. 1999. Comparing global models of terrestrial net primary productivity (NPP): analysis of differences in light absorption and light-use efficiency. Global Change Biology 5:56-64.

Ruimy, A., B. Saugier, and G. Dedieu. 1994. Methodology for the estimation of terrestrial net primary production from remotely sensed data. Journal of Geophysical Research: Atmospheres 99:5263-5283.

Running, S. W., R. Nemani, J. M. Glassy, and P. Thornton. 1999. MODIS daily photosynthesis (PSN) and annual net primary production (NPP) product (MOD17), algorithm theorectical basis document, version 3.0, April 29, 1999. $\langle$ http://modis.gsfc.nasa.gov/〉

Running, S. W., P. E. Thornton, R. Nemani, and J. M. Glassy. 2000. Global terrestrial gross and net primary productivity from the earth observing system. Pages 44-57 in O. E. Sala, R. B. Jackson, H. A. Mooney, and R. W. Howarth, editors. Methods in ecosystem science. Springer-Verlag, New York, New York, USA.

Serrano, L., S. L. Ustin, D. A. Roberts, J. A. Gamon, and J. Penuelas. 2000. Deriving water content of chaparral vegetation from AVIRIS data. Remote Sensing of Environment 74:570-581.

Tucker, C. J. 1979. Red and photographic infrared linear combinations for monitoring vegetation. Remote Sensing of Environment 8:127-150.

Weiss, A., and J. M. Norman. 1985. Partitioning solar radiation into direct and diffuse, visible and near-infrared components. Agricultural and Forest Meteorology 34:205213.

Wofsy, S. C., M. L. Goulden, J. W. Munger, S. M. Fan, P. S. Bakwin, B. C. Daube, S. L. Bassow, and F. A. Bazzaz. 1993. Net exchange of $\mathrm{CO}_{2}$ in a mid-latitude forest. Science 260:1314-1317.

Wolfe, R. E., M. Nishihama, A. J. Fleig, J. A. Kuyper, D. Roy, J. C. Storey, and F. S. Patt. 2002. Achieving subpixel geoloation accuracy in support of MODIS land science. Remote Sensing of Environment 83:31-49.

Xiao, X., S. Boles, S. Frolking, W. Salas, B. Moore, C. Li, L. He, and R. Zhao. 2002a. Observation of flooding and rice transplanting of paddy rice fields at the site to landscape scales in China using VEGETATION sensor data. International Journal of Remote Sensing 23:3009-3022.

Xiao, X., S. Boles, J. Y. Liu, D. F. Zhuang, and M. L. Liu. $2002 b$. Characterization of forest types in northeastern China, using multi-temporal SPOT-4 VEGETATION sensor data. Remote Sensing of Environment 82:335-348.

Xiao, X., B. Braswell, Q. Zhang, S. Boles, S. Frolking, and B. Moore. 2003. Sensitivity of vegetation indices to atmospheric aerosols: continental-scale observations in Northern Asia. Remote Sensing of Environment 84:385392.

Xiao, X., D. Hollinger, J. D. Aber, M. Goltz, E. A. Davidson, and Q. Y. Zhang. 2004a. Satellite-based modeling of gross primary production in an evergreen needleleaf forest. Remote Sensing of Environment 89:519-534.

Xiao, X., B. Moore, X. Qin, Z. Shen, and S. Boles. $2002 c$. Large-scale observations of alpine snow and ice cover 
in Asia: using multi-temporal VEGETATION sensor data. International Journal of Remote Sensing 23:22132228.

Xiao, X., Q. Zhang, B. Braswell, S. Urbanski, S. Boles, S. C. Wofsy, B. I. Moore, and D. Ojima. 2004b. Modeling gross primary production of a deciduous broadleaf forest using satellite images and climate data. Remote Sensing of Environment 91:256-270.

Zarco-Tejada, P. J., C. A. Rueda, and S. L. Ustin. 2003. Water content estimation in vegetation with MODIS reflectance data and model inversion methods. Remote Sensing of Environment 85:109-124. 